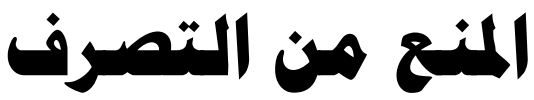

\section{هحاولة نظرية نحو رسم الحدود الفاصلة بين الحق في التصرف والقدرة القانونية على التصرف}

shel

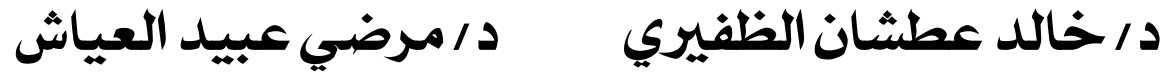

أستاذ القانون المدني المساعد أستاذ القانون المدني المساعد

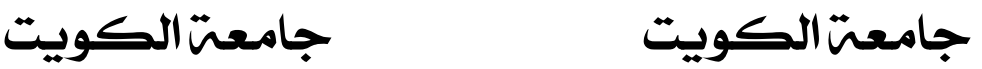




\section{هقدهة}

مـا مـدى إمكانيـة التزام الفرد ـأمسام أي شـخص آخر- بالتــــل عن التصرف

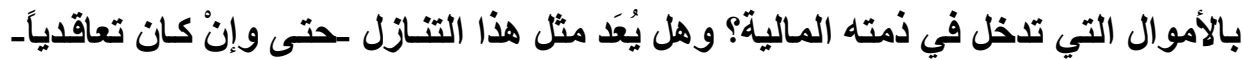
صحيحاً ومشروعاًٌ إن هذا السؤال يحمل في طياته مفارقة واضحة تلتعلق بمـا إذا كـان الفرد قادراً على حرمان نفسه من حرية التصرف في أموالهه وذلكك من خلال ممارسته

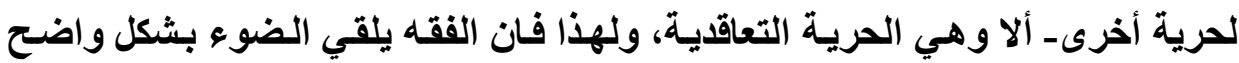

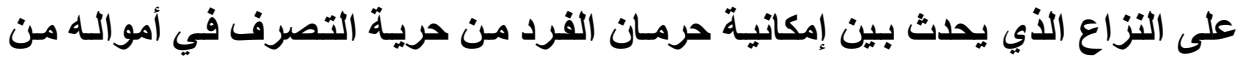
خلال الحرية العقدية.

يظهر بشكل واضـح أن صحة الشرط المـاتع من التصرف ذي الطبيعة العقديـة

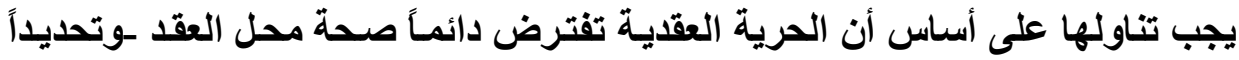
محل الالتزام-أو مشروعيته('). ولكن الشرط المانع من التصرف يدعونا بالضرورة إلى

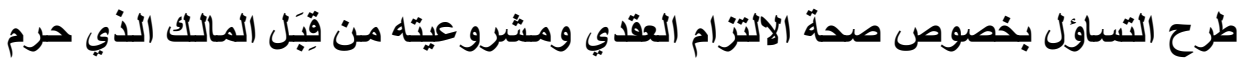

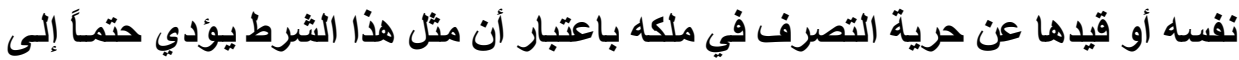

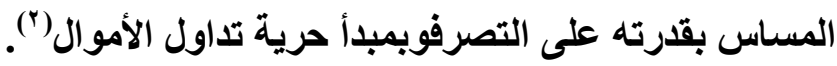

( ) ( انظر في ذلك : (1)

D. Berra, Le principe de libre disposition des biens en droit civil, Contribution à la notion d'indisponibilité juridique, these, Nancy, 1969, ler vol., p. 156 ; sur la distinction entre la licéité de l'objet du contrat et celle de l'objet de l'obligation, V. H., L. et J. Mazeaud, Leçons de droit civil, t-2, vol. 1- Obligation : théorie générale, Montchrestien, 9 éd. Par F. Chabas, 1998, n. 231 et s.

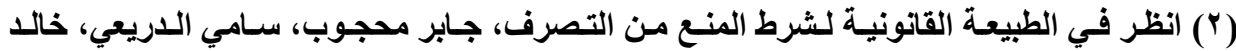

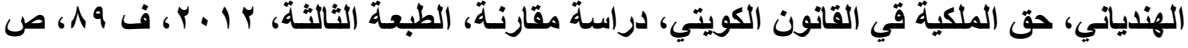




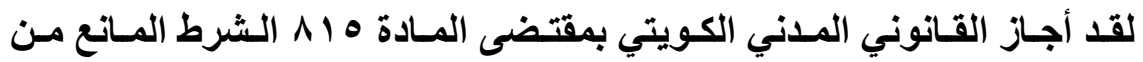

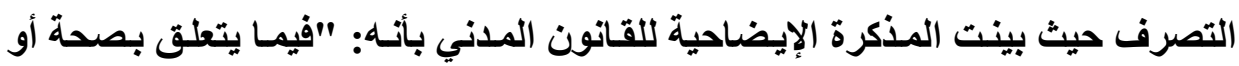
عدم صحة مثل هذا الشرط، نجد ـ سواء في فقه الشريعة الإسـلامية أو في القوانين الوضعية ـاتجاهين أحدها ينتهي إلى عدم صحة الشرط، والثاني إلى صحته. فالشرط

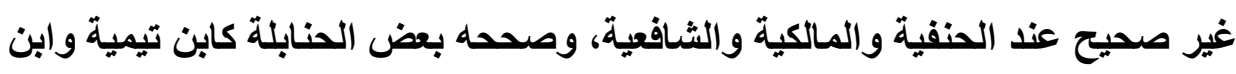

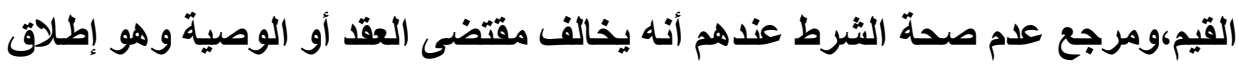

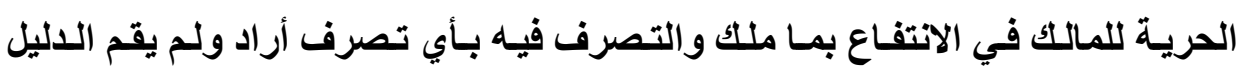

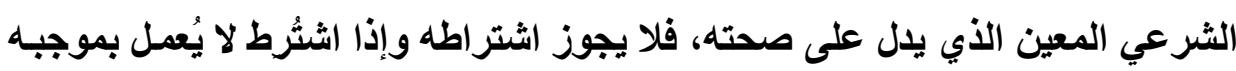

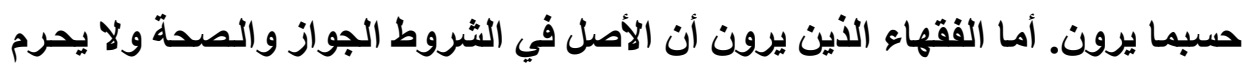

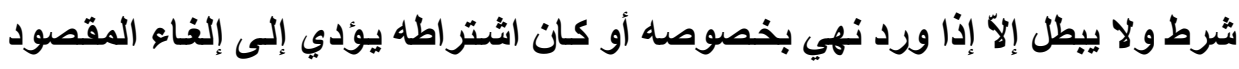

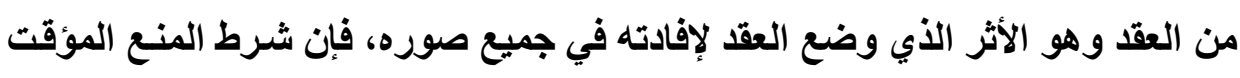

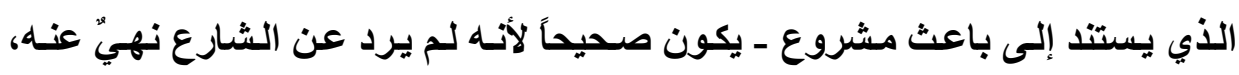

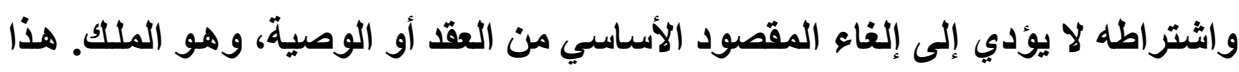

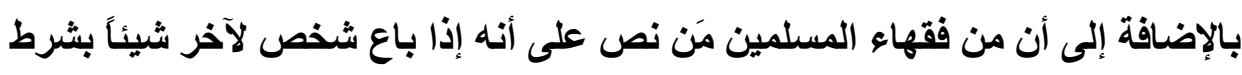

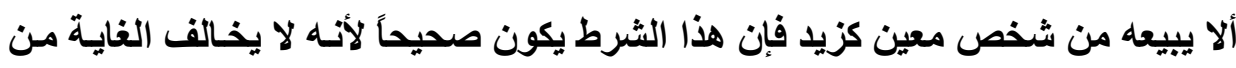

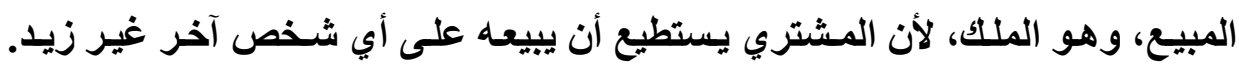

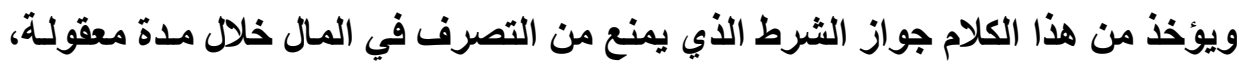

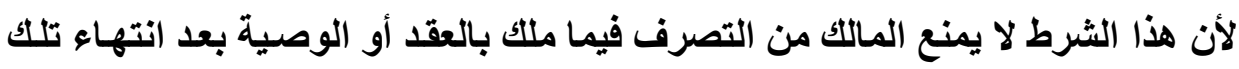
المـدة، وعلى هـا لا يكـون اشـتراطه مخالفـاً لمقتضى العقـــ أو الوصسية وهـو الغايـة المقصودة من كل منهما، وقد آثر المشروع الأخذ بهذا الرأي" ل(").

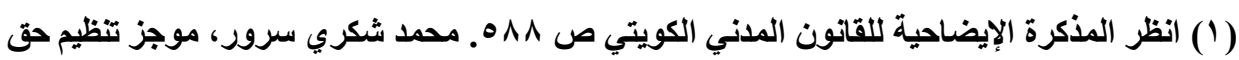

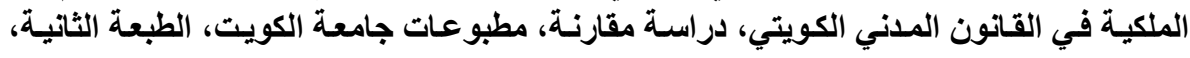




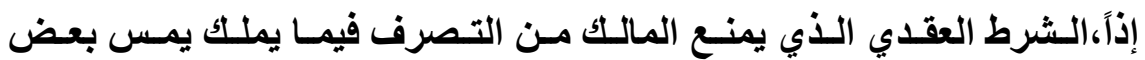

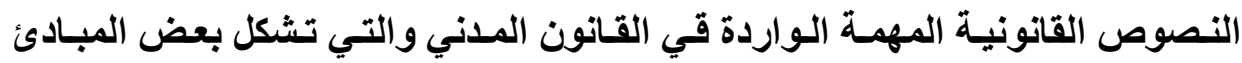

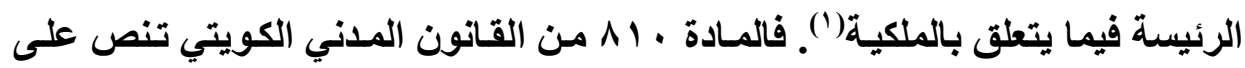

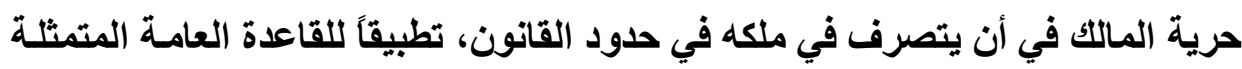

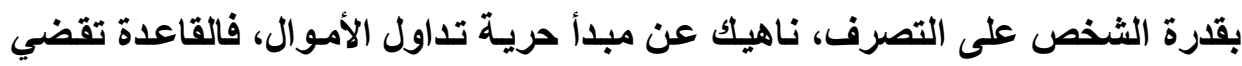

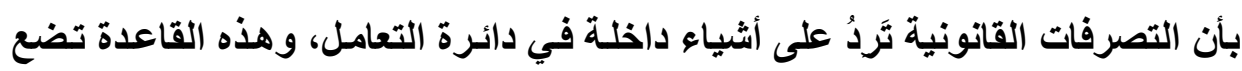

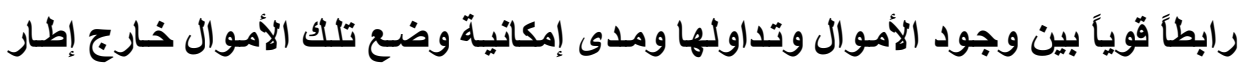
دائرة التعامل من خلال منع التصرف فيها إرادياً.

تلكك المبادئ تشكل عدداً من الحجج المهمـة التي يمكن اللجوي إليها لمناقشة

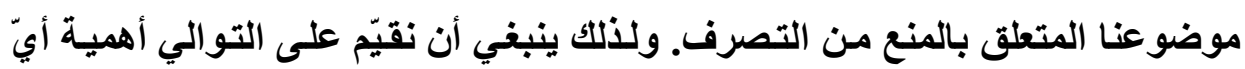

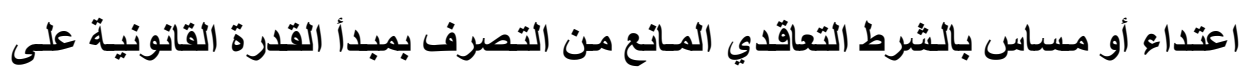

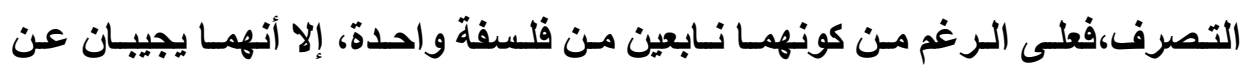
تساؤلات مختلفة كما سنرى. لذا،من الأهمية بمكان أن نتساعل عن مدى شرعية حظر التصرف التعاقدي من

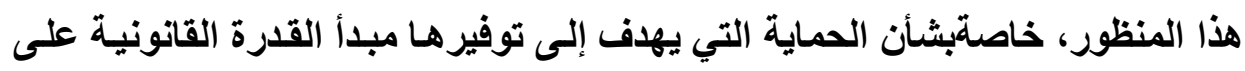

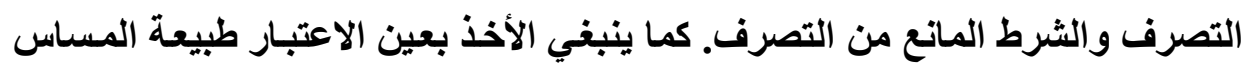

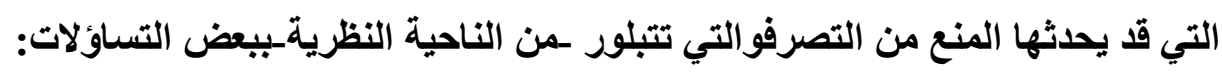
- بداية، هل من الممكن أنتُعدّ الثرط العقدي المانع من التصرف يؤثر مباشرةَفي

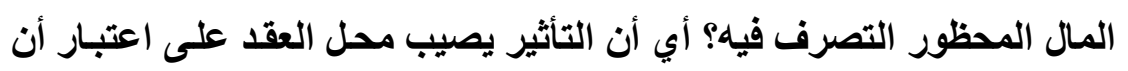

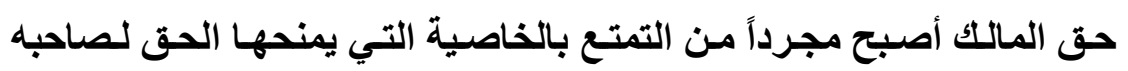
وبخاصةٍ حق التصرف؟

( (1) انظر، ليلى عبدالله سعيد، دور الإرادة في تقييد حق الملكية، مجلة الحقوق، ديسمبر ب ب 19 1، السنة

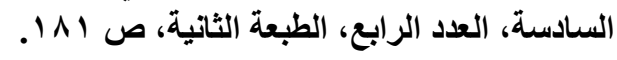




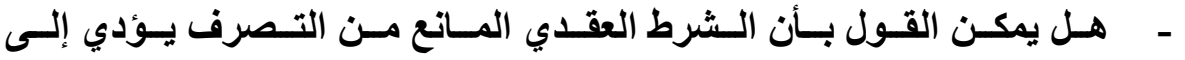

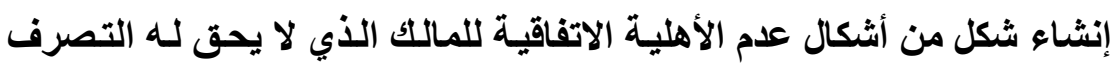

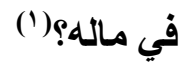

- أخيراً، هل يمكن النظرفي الثرط العقدي المـانع من التصرف على أنـه يضع

التزاماً بالامتناع عن عمل على عاتق المالك؟؟(آ)

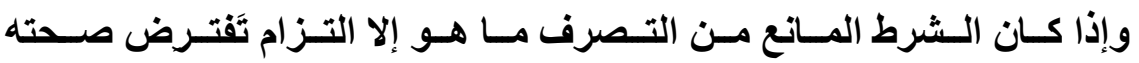

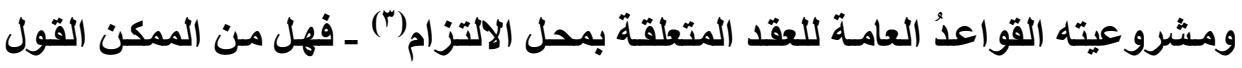

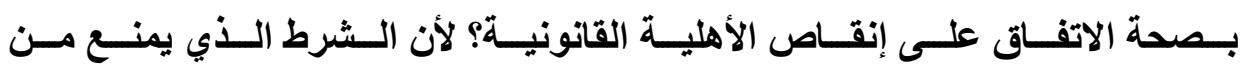

التصرف يتعارض مع بعض نصوص القانون المدني. فالمـادة ؛ ^ من القانون المدني

: (1) (انظر في ذلك (1932,

L. Josserand, Cour de droit civil positif français, t-1, Sirey, 2 ed., 1932,

n. 1850

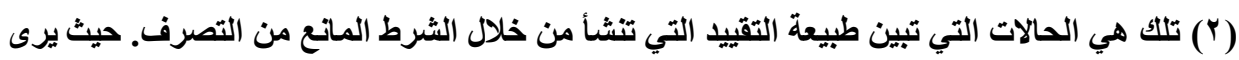

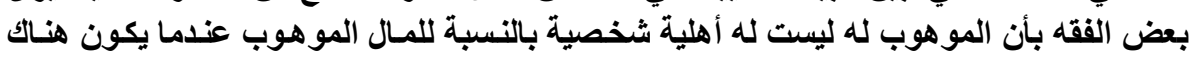

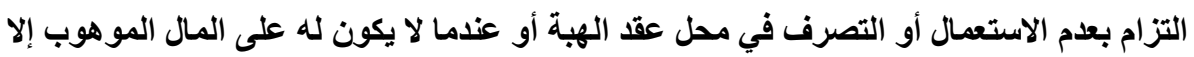

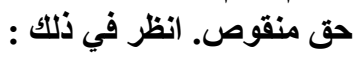

A. Chéron, La jurisprudence sur les clauses d'inaliénabilité : RTD civ. 1906, p. 345 ; Y. Le Roux, Des prohibitions d'aliéner insérées dans les contrat et testaments, thèse, Rennes, 1930, p. 90.

(T) المادة ه المن القانون المدني الكويتي تتص على أنه "يجوز أن يتضمن العقد أي شرط يرتضيه

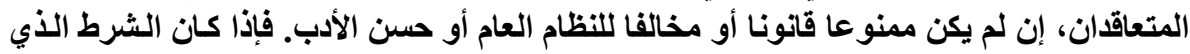

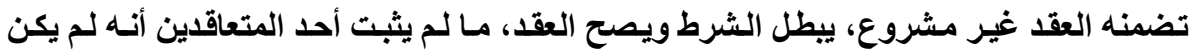

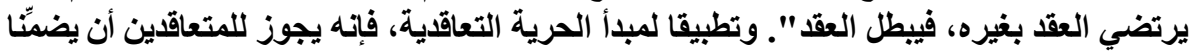

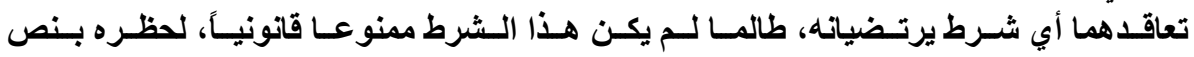

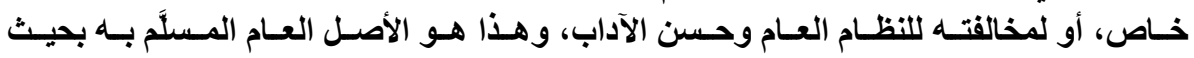

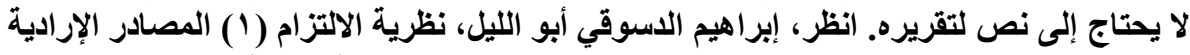

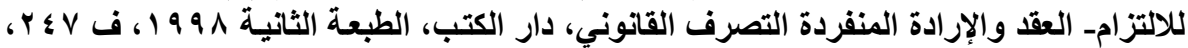


الكويتي تنص على أن "كل شخص أهل للتعاقد، مـا لم يقرر القانون عدم أهليته أو

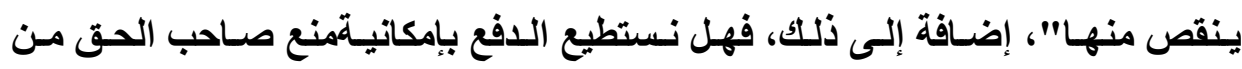

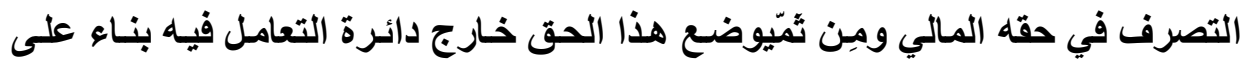

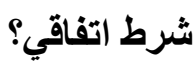

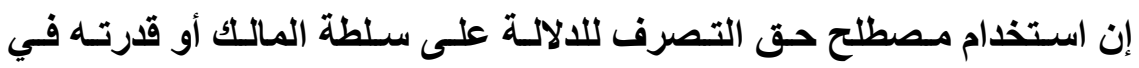

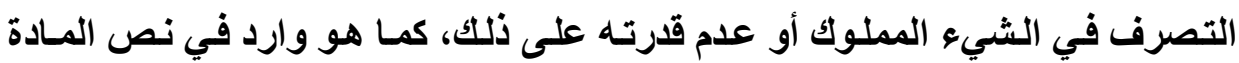

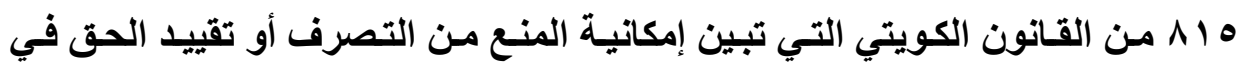

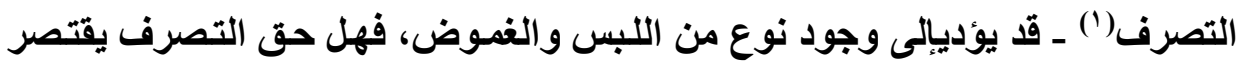

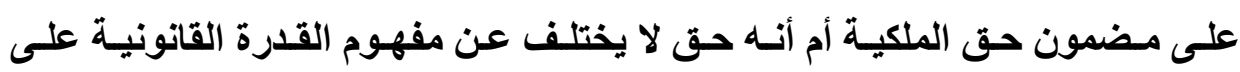

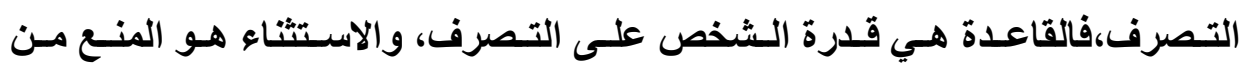

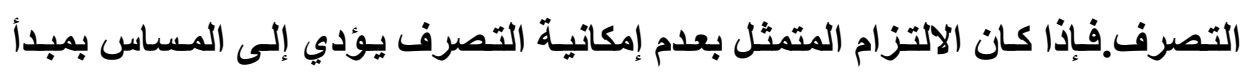

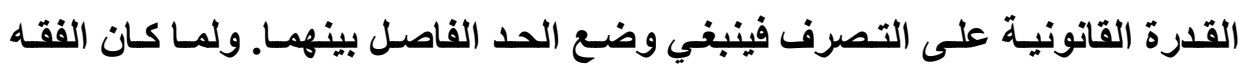

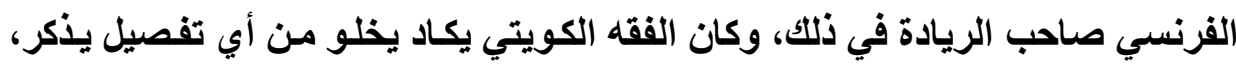

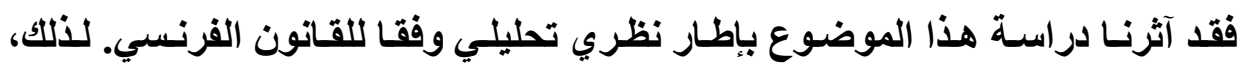

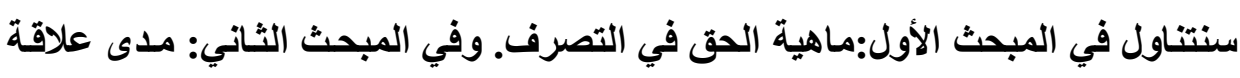
المنع من التصرف بعدم الأهلية.

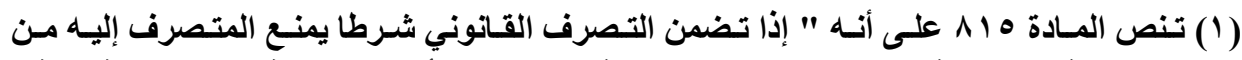

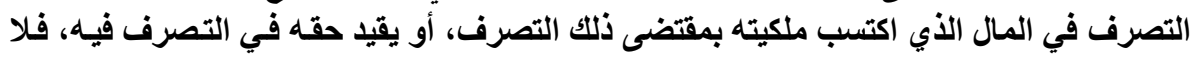

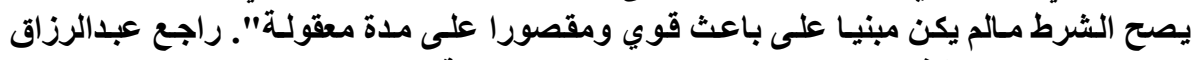

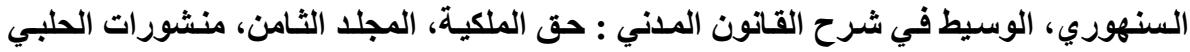

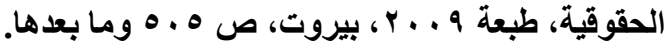




\section{المبحث الأول

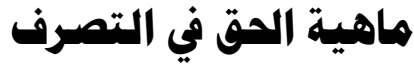

يُعَدِّ مبـدأ القدرة القانونيـة على التصرف مـن المبـادئ الأسساسية والجوهريـة

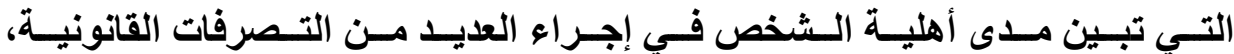
لذلك فإندراسةوتحديد ماهية الحق في التصرف الذي قد يُحرم منـه صـاحبه بسبب القيد الناتج عن الثرط المانع من التصرف ستكون في ضوء تحديد مفهوم القدرة القانونية على التصرف(المطلب الأول)قبل أن نتطرق إلى عناصر الحق في التصرف (المطلب الثاني).

\section{الاطباب الأول}

\section{هفهوم القدرة القانونية على التصرف}

القدرة القانونية للشخص على التصرف في أمواله تشير إلى فكرة أن الثخص

إذا لم يكن عديم الأهلية بمقتضى القانون فيجب أن تكون له الاستطاعة في التصرف في الأمـوال التي تشكل ذمتـه الماليـة تطبيقاً لمبـدأ الحريـة التعاقديـة التـي يكفلهـا القـانون المدني،فالامَ تشير فكرة إمكانيـة التصرف بحريـة في الأموال؟ هل نتصرف في أشياء مادية أوخلاف ذلك في حقوقفير مادية؟ وما هي طبيعة هذا الامتياز؟ أهو امتياز خارج عنطظق حق الملكية الذي تختلف مسمياته بين حق التصرف والقرة على التصرف؟(')

(1) V. D. Berra, Le principe de libre disposition des biens en droit civil, Contribution à la notion d'indisponibilite juridique, thèse, Nancy, 1969, 2 vol, p. 109. 
هنايك من يرى أن الامتياز الذي يسمح للشخص القادر على التصرف بحريـة في

أمواله المكونة لذمته المالية يختلف تماماً عن حق تصرف المالك والذي لا يهتم سوى

بمضمون حق الملكية، في حين أن القرة على التصرف هو امتيـاز متصل بالثخصية

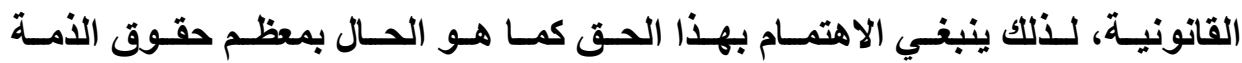

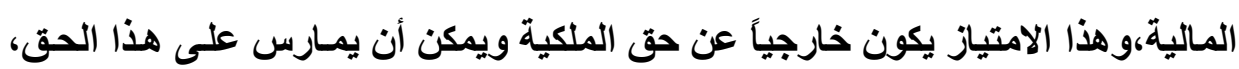

وبناء عليه، يفضل بعض الفقه أن يوصف هذا الحق بالقدرة على التصرف، ولا يرجع

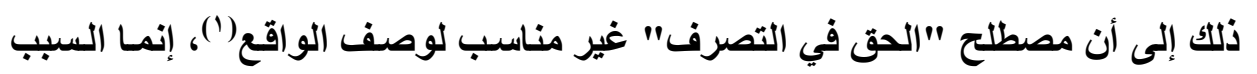

الأساسي هو الالتباس الذي يمكن أن تسببه هذه المصطلحات، وهكذا فإن حق التصرف

يثير إلى حق التصرفذاته في الملكية، في حين أن القدرة على التصرف لا تخضع كمـا

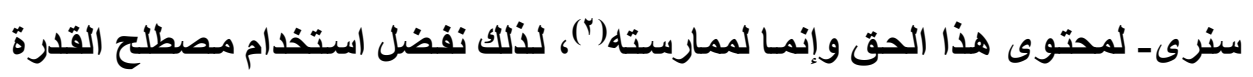

على التصرف بصفته ذا صلة مباشرة بالشخص فئ")

(1)

V. notamment F. de Visscher, Du « jus abutendi » : RTD civ. 1913,337.

( ( $)$

E. Gaillard, La notion de pouvoir en droit privé, Economica, 1983, n 64

; J. Carbonnier, Droit civil, t-1- les personnes, PUf, $21^{\mathrm{e}}$ éd., 2000, p. 101 ;

P. Roubier, pour qui « essentiellement le pouvoir est un prérogative qui permet à une personne d'empiéter sur la sphère juridique d'autrui ". Les prérogatives juridique : APD 1960, p. 79. Selon R. Bonnard, «le pouvoir implique la libre appréciation quant à la décision à prendre ». Les droits publics subjectifs des administrés. RD pub. 1932, p. 714.

(r) مصطلح القدرة يثير إلى حرية ممارسة الامتياز بالنسبة للشخص.

V. D. Berra, thèse, précitée, p. 144. 


\section{أولا:المذهوم التقليدي للقدرة القانونية على التصرف}

يمكن تلخيص المفهوم الفقهي السائد خلال القرن التاسع عشرفيما يتعلق بقدرة

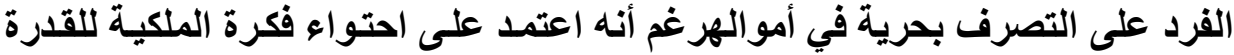

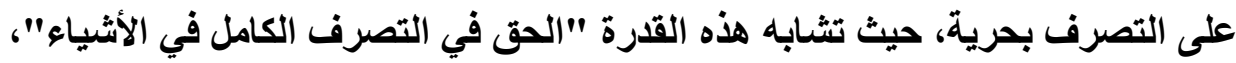

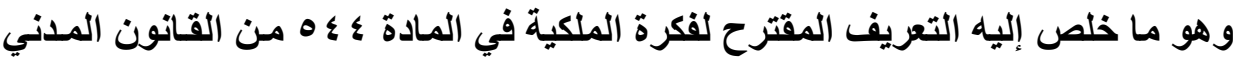

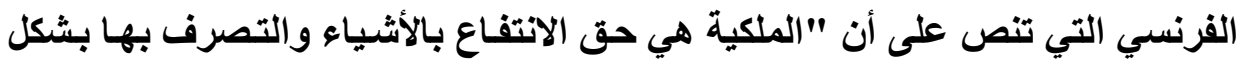

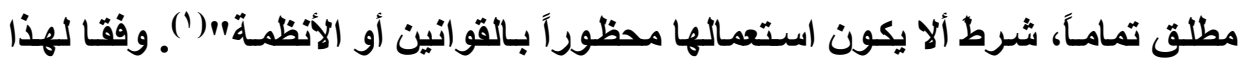

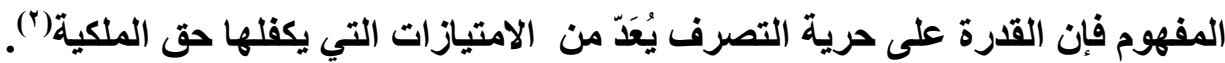
هذا المفهوم التقليدي كان محل انتقاد من قبل بعض الفقه الفرنسي، فهنـاك من

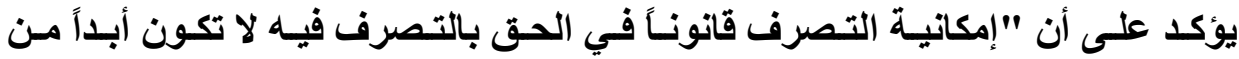
امتيازات الملكية، لأن قابلية الحق للانتقال أو التحويل صفة مشتركة من حيث المبدأ

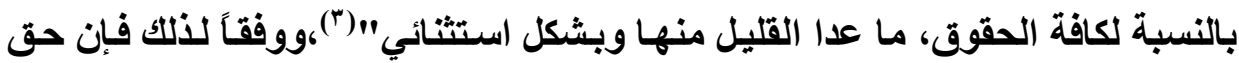

(1) يرى بعض الفقه أن هناك تشابه و اضح بين قدرة الشخص على التصرف في الأموال ومفهوم

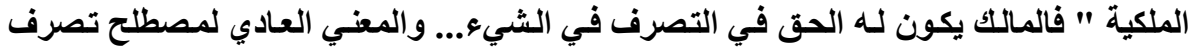

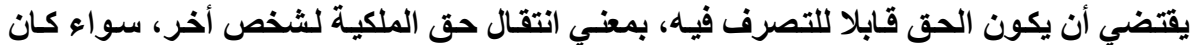
الانتقال بين أثخاص أحياء أو من خلايل الوصية. انظر فئه

Ch. Aubry et Ch. Rau, Cour de droit civil francais, t-3, 4e éd., Paris $1869, n^{\circ} 190$.

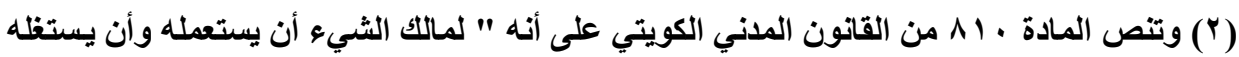

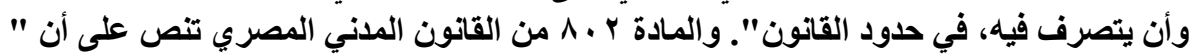

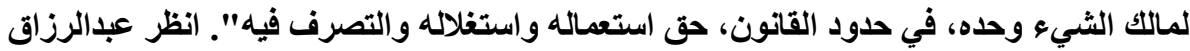

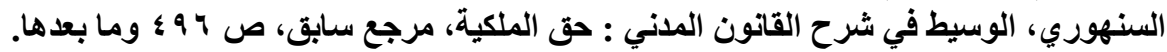

M. Planiol, Traité élémentaire de droit civil, t-1, LGDJ, $6^{\mathrm{e}}$ éd., 1911, note 1, p. 727. 
الملكية يتضمن امتياز التصرف قانوناً في الثيء المملوك من بين الامتيـازات الأخرى المختلفة التي يخولهـا هذا الحق، إذ إن حق الملكيـةكمثل سـائر حقوق الأمـة الماليـة الأخرى-: محل القدرة على التصرف، أي ما ترد عليه القدرة في التصرف، فهو شيء خارج عنها.

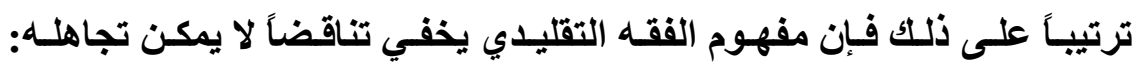
فكيف نسوّغ أن القدرة على التصرف يمكن أن تكون صفة لحق الملكيـة، وهو حق عيني من بين الحقوق العينية الأخرى، في حين أنهاه من الواضـح أن هذه القدرة يمكن

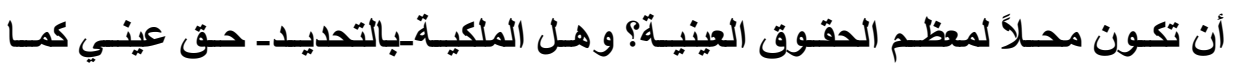

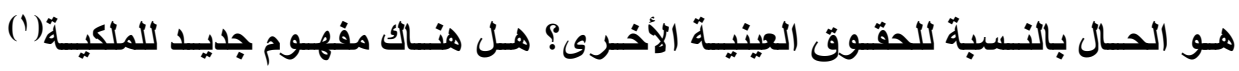
ينـادي بعض الفقـه بتوسيع المجـال التطبيقي لهذهـ الملكيـة ليشمل مجموعـة الحقوق وليس الحقوق الماديـة فقط، ليبعد التنـاقض الذي يشوب المذهب التقليدي؟ لقد سـاند

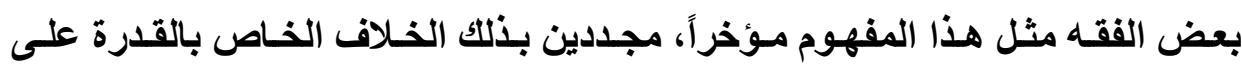
التصرف القانوني.

\section{ثانيا: المفهوم المعاصر للقدرة القانونية على التصرف}

إن مضمون حق الملكية ـوفق النظرية القديمةـ يقتصر على الأشياء المادية، إلا

أن بعض الفقه المعاصر قد رفضوا مثل هذا التحديد لمضمون حق الملكية ورأوا أنـه يمكنه أيضاً التعرض إلى الأشياء الماديـة والمعنويـة كذلك، وأن مجموع حقوق الأمـة المالية تخضع له أيضاً.

(1)

F. Zénati, Pour une rénovation de la théorie de la propriété, RTD civ. 1993, 305. 
يعـارض الفقيـهinossar التميـز الثنـائي التقليــي لحقـوق الـشخص بـين

الحقوق العينية والحقوق الثخصية(')، فهو يرى أن حق الملكية هو الحق الوحيد بين

الحقوق العينية الذي لا يجعل لمالك الحق علاقة قانونية مع شخص معين، في حين أن مجموع الحقوق العينية الأخرى تجعل بين صـاحب الحق ومالك الشيء علاقة إلزامية لأنها تُعنى بثيع مملوك للغير('). أمسا الملكية "فهي ليست سوى العلاقة التي تجعل

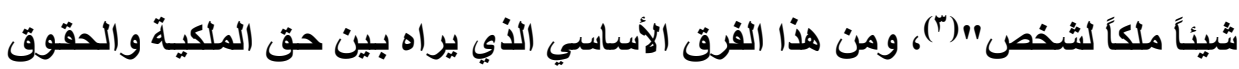
العينية الأخرى يصل Ginossar إلى نتيجتين تمثثلان شِيَّي فكرتها: الشثق الأول هو أن الن حق الملكية يصف العلاقة بين الشخص وكل عنصر من عناصر شروتـه، وهذه العلاقة التي يصفها "بالمطلقة"، لأنها تتميز بالتحكم الكامل في الشيء وحجيتها في مواجهة غيره، لا تخص الأشياء المادية فقط بل تخص أيضاً مجموع الحقوق العينية والشخصية وحقوق الأمة المالية(؛).الشث الثاني هو أن الحقوق العينية غيرُ حق الملكية، ولأنها قـ

(1)

S. Ginossar, Droit réel, propriété et créance- Elaboration d'un système rationnel des droits patrimoniaux, LGDJ, 1960.

" Tout comme le droit personnel est celui qui correspond à une obligation personnelle, il faut entendre par droit réel le droit qui correspond à une obligation réelle. Ibid., $\mathbf{n}^{0} 36$.

Ibid., $\mathbf{n}^{0} 12$.

Ibid., $n^{0}$ 13. V. aussi l'article du même auteur, pour une meilleure définition du droit réel et du droit personnel: RTD civ. 1962, p. 578. 
تولد التزامـات عينية، فهي تنشئ أيضاً بنفس طريقة الحق الشخصي علاقة توصف "بالنسبية" بين شخصين معينين.

يرى Ginossar من هذه العلاقة الثنائية التي تخص مجموع الحقوق العينية باستثناء الملكية إلى أن "الصلة بين الملك والحق العينـي ليست هيكلاً خياليـاً ولكنها تنبع من علاقة قانونية ثنائية..."(')وتعكس الانتمـاء بين الشيء ومالكهـ وتوفر الإطـار الأقضل الذي يمكن أن تدخل فيه القدرة على التصرف والتي قلنـا إنها مرتبطة بشكل وثيق بالشخصية القانونية. وعلى الرغم من بعض التردد، فلا يجرؤ Ginossar على استخلاص كل النتائج التي تدعوها إليه نظريته: فهو يساند أفكار Planiol حيث يؤكد أنـه من الصحيح تمامـاً أن "إمكانيـة التصرف قانونـاً في الحق بـالتخلي عنـه لا ترتبط

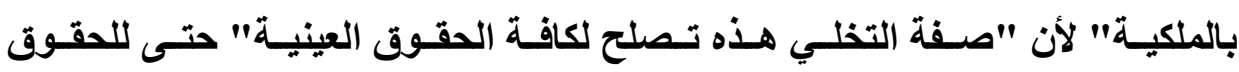
الثخصية(؟) و هنـاك مسن يـرى أنGinossar ينـاقض نظريتـه الخاصسة والتـي تتميز بفكرة أنّ الملكية تتعلق بمجموع الحقوق الثخصية أو العينية، على اعتبار أن مفهوم

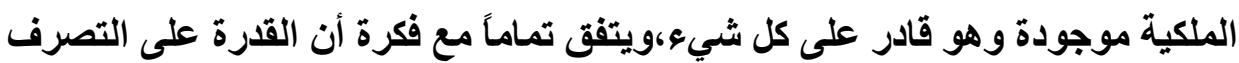

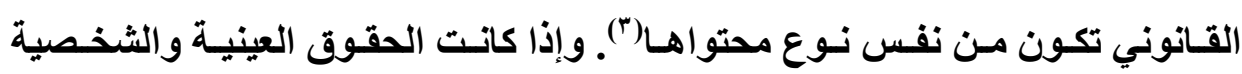
تثكلان حق الملكية، فإن نظرية إمكانية التخلي عن تلك الحقوق لم تصبح مزعجة بـل

S. Ginossar, Droit réel, propriété et créance- Elaboration d'un système rationnel des droits patrimoniaux, LGDJ, 1960. n.42.

Ibid., p.31.

V. F. de Visscher, Du " jus abutendi" RTD civ. 1913, p. 341. 
مستحسنة، فلا يتم بذلك إزالة التعارض الواقع في قلب المذهب التقليدي فحسب،بل إن موضـوع حق الملكيـة هـو مجموع حقوق الأمـة الماليـة مـن جهـة، وأن القدرة على التصرف القانوني حق المالك وحده من جهة أخرى، يعززان أحدهما الآخر، وهذا هو ما هون هون

يقترحه الفقيه Zénati (')

في الوقت الذي يشاطر فيه Zénati رأي Ginossar، يقابله هو بـاعتر اض دقيق آخر وهو أنه لم يعق فكرته إلى الحد الذي كان يجب أن يصل إليه، أي إلى رفض

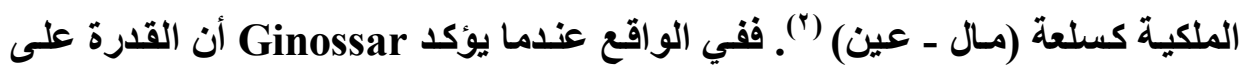
التصرف القانوني ليست صفة لحق الملكية، فهو يعتمد الفكرة المضادة لتلك التي أراد الدفاع عنهـا وهـي أن العلاقة الخاصـة التي تربط بيل الشخص ومجمـل أموالهسواءً كانت ماديـة أو معنويـة، ليست كلهـا مشمولة في مفهوم حقوق الأمـة الماليـة، وهي العلاقة التي طالما تم تأكيدها، وهكذا فالملكية تلخل في إطار حقوق الأمة الماليـة، وهو

ما يتفق مع النظرية الفقهية التقليدية.

ولكن Zénati يؤكد بوضوح تام على أن القدرة على التصرف قانونـاً في المـال

هي من حق المالك فقط، وذلك من أجل الفصل بين القدرة والملكيـة.ولكن إذا افترضنا أنه يجب إبعاد هذا التفسير الأخير لنفضل تفسير Zénati، فيجب علينا أن نقدّر ما الذي إني يجب أن نأخذه من فكرة أن القدرة على التصرف لا يمكن تخيلها خـارج حق الملكية، وتستتد هذه الفكرة على أساسين:أولاً: هو أن الملكيـة تقع ليس فقط على الأشياء المادية، بل على مجمل حقوق الذمة المالية، وهنا يتبنى Zénati التحليل الذي قام بـه

F. Zénatie, pour une rénovation de la théorie de la propriété : précité, p. 318.

(2) Ibid., p. 305. 
Ginossar الامتيازات القانونية (للأول على الثاني) يفوق محتواها القدرة على التصرف ويمكن أن يشمل خاصة القدرة على التعاقد. ولا يتراجع Zénati أمام هذه الحجة ويقود فكرته إلى الى نهاية منطقه ولا يتردد في التأكيد على "أن كل نشاط قانوني يظهر في النهاية كأنـه تفعيل لصفة من صفات الملكية"(").

وهناك من يرى أنّ مثلّ هذا المفهوم لحق الملكية الموسـع فيمـا يخص موضوع ومضمون هذا الحق لا يستطيع أن يوفر تفسيراً مقنعاً يمكن أن يوضـح مفهوم حريـة

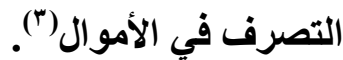

في الحقيقة، إنـالقدرة القانونيـة على التصرفتُعَّاحدى الروابط الأساسية التـي تزبط بين الشخص وذمته المالية ويمكنها التعرض لمعظم الحقوق الواردة في الأمـة المالية(؛). ويجب تمييزها تماماً بهذا التعريف عن السلطة الماديـة على الأشياء والتي تعتمد على محتوى الحقوق المختلفة على هذه الأشياء(ه).

(1) Ibid., p. 320.

(2) Ibid., p. 320.

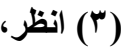

M. villey, Critique de la pensée juridique moderne, Dalloz, 1976, p. 190.

(4) Il a étéexactment remarqué que le pouvoir de disposition " n'est pas attachée à la chose, il appartient à la personne". P. Guiho, Les actes de disposition sur la chose d'autrui : RTD civ.1054,1, note12.

(5) M. Aubert a qualifié d'exacte et utile la distinction entre " la maîtrise de la chose, conférée par le droit de propriété stricto sensu, et la maîtrise du droit lui-même" Le droit de disposer de l'immeuble, in Etude Flour, Defrénois, 1979, p. 1 et s., n. 2. 


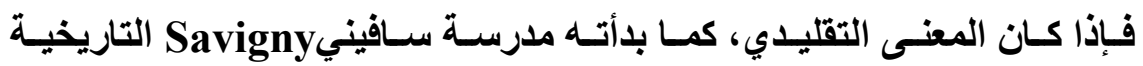
والألمان في القرن التاسع عشر ، تُعَدّالحق الثخصي عبارة عن سلطة أو حق إرادي

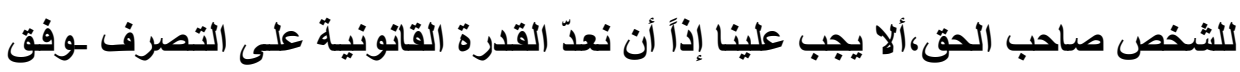

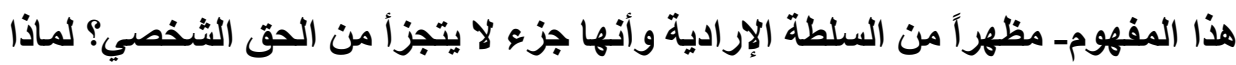

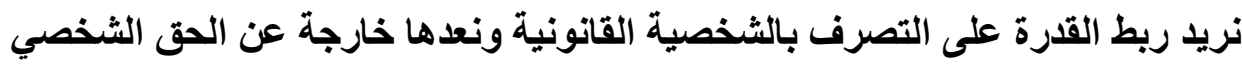
إذا كان هذا الأخير مجرد تعبير عن هذه الثخصية:كيف يمكن تفسير أن شخصاً عديم الأهلية ليس لله إرادة يمكن أن يكون صاحب حقوق شخصيةج؟ وكذلك بشأن النظريـة الثخصية الاعتبارية حيث إن الحق الثخصي سلطة إرادية، لذلك صاحب الحق الثق الوحيد هو الثخص الطبيعي الذي يكون قادرأعلى التعبير عن الإرادة. يمكن لنا أن نستخلص مما سبق الإشارة إليه، أن الحق الثخصي مختلف تمامساً

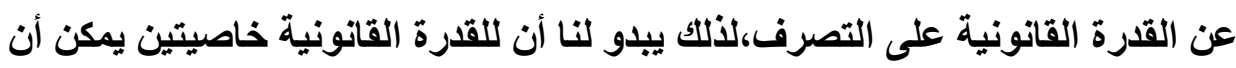

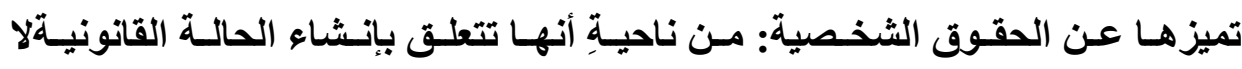

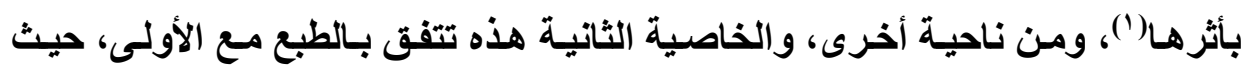

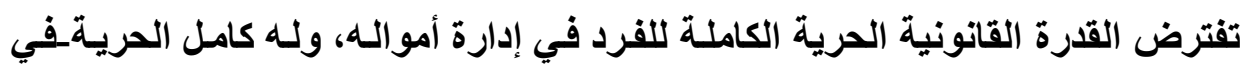

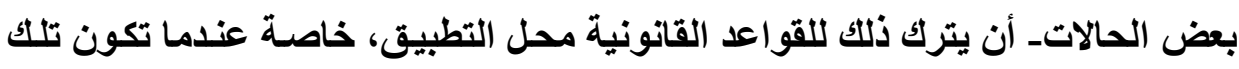
القواعد القانونية مكلمة وليست آمرة(")، وبالطريقة نفسها سيكون لايهه دائمـاً الحريـة

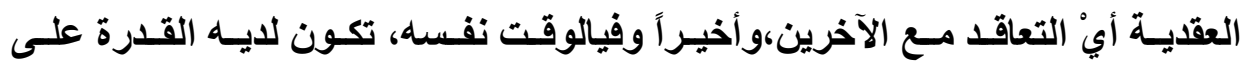

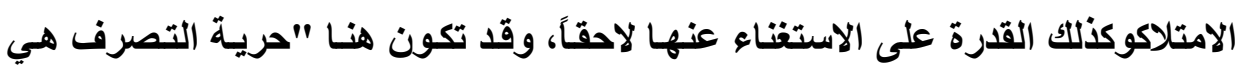

(1) V. P. Roubier, Les prérogatives juridiques : précité, p. 99.

(2) V. Rouast, Les droits discrétionnaires et les droits contrôles : RTD civ. 1944, n. 4. 
أيضاً حريـة عدم التصرف"(')، وهذه هي القدرات القانونية. ومن أجل تمييزهم عن

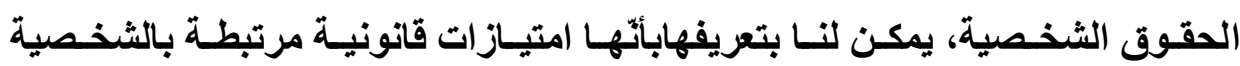
القانونية، أما الدق الشخص فهو عنصر في الأمة المالية. فأمام صاحب حق شخصي نجد شخصاً، ويوصف الحق هنـا بـالالتزام، أو نجد شيئًا ويوصف الحق بـالعيني،وأمسام صساحب القدرة لا يوجد إلا الثخصنفسه، فالقدرة موجودة قبل التصرف القـانوني، وهي تعد في هذا السياق تعبيراً عن الثخصية: إن

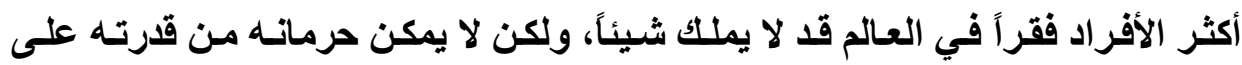
الامتلاك والتصرف، وهنا يكمن كل الفرق بين القدرة، وهي الامتيـز الموجود في كل إنسان، وبين الحق الثخصي الأي هو عنصر في ذمتهالمالية.

\section{الاطباب الثاني عناصر الهق في التصرف}

معظم الحقوق المكونة للأمة المالية للفرد يمكن أن تكون محلا للتصرف، وحتى يكون صاحب الحق قادرا على التصرف يجب توافر عنصرين: الأول:الأي يمكن وصفه بأنه جوهري، يرجع إلى الصفات الخاصة بالحق الذي يرد عليه التصرف، والتي يمكن

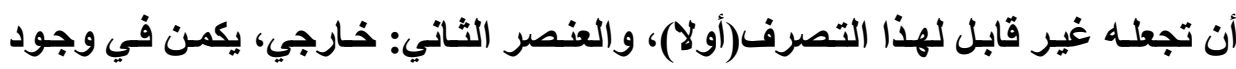
علاقة ملكية بين الحق وصاحبه (ثانيا).

(1) A. Piedelievre, Promesse unilatérale de vente immobilière et prénotation : Déferions 1975, a. 30 960, p. 977. 


\section{أولا: العنصر الجوهري: الصفة المالية للحق المتصرف فيه}

ينظر إلى القدرة القانونية على التصرف دائماً على أنها يمكن أن تمـارس على مجموع الأموال والحقوق المكونة للامة المالية لصاحبها، فالملاعمة بين وجود مال في الأمة المالية وإمكانية تداوله قوية لارجة أن تكييف الذمـة الماليـتتعطى لكل حق يمكن تـاولـه ونقلـهـه. وهذا بالفعل "مبدأ أساسـي للحق الفردي بـأن الحقوق يمكن نقلهـا أو

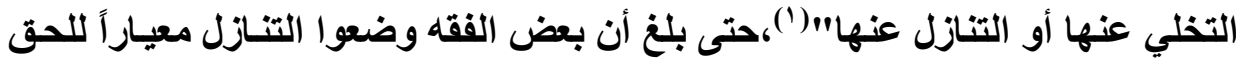
الثخصي: فمفهوم الحق الثخصي يفترض التعلق بالأمـة الماليـة، فإمكانيـة التنـازل عنه: إمكانية التصرف والتخلي قانونـاً عن حق مـا شرطاً من شروط الاعتراف بهذا الحق كحق حقيقي (†):"و إنه بناءً على هذا العنصر وحده يمكنتا الحديث عن حق كعين يمكن تملكها"(")، وعلى أسـاس هذا المعيـار، يرفض بعض الفقهـ أن يصف الحق في الاسم بحق شخصي"(؛)، كما يرفض هذا الوصف لجميع حقوق الشخصية(ْ).

وقد انتقدت هذه النظرية لكونها تعطي نظرة ضيقة جداً عن الحقوق الشخصية.

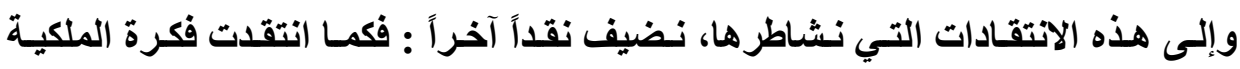
المطبقة على مجموع الحقوق الثخصية، هناك أيضاً من يشجب النظرة التي يقدمها Roubier

(1) J.Carbonnier, Droit civil, Introduction, précité ,n. 184

(2) H. Capitant, Sur l'abus des droits, précité, p. 373.

(3) P. Roubier, Le rôle de la volonté dans la création des droits et des devoirs: APD t-3, p. 5.

(4) Ibid., p. 29.

(5) P. Roubier, Les prérogative juridiques, précité, p. 74 
يتسع إلى جانب الحقوق التي تدمج قيمة مالية للحقوق الثخصية ذات القيم المعنويـة

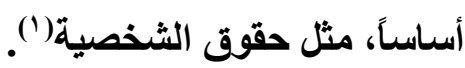

وبعد أن تم رفض فكرة أن إمكانية التنازل متأصلة في الحقوق الثخصية وأنْ ليس في هذه الحقوق مكان للحقوق التي توصف بخارجة عن الذمة المالية، فإذا كان التعلق بالذمة الماليةكما رأينا- عاجزاً عن تعريف الحقوق الثخصية، فليس من المؤكد

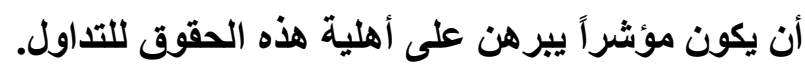

إن الصلة بين تطلق الحقوق بالذمة المالية وإمكانيتها للتصرف فيها حقيقة)(") لا يمكن نفيها ولا التثكيك فيها")، ولكن في الواقع يبدو الحد الفاصل بين الحقوق غير بالير

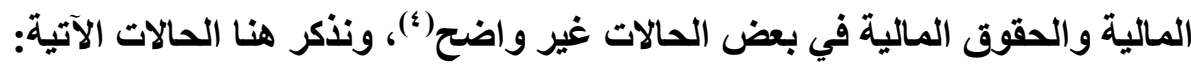
- في بعض الأحيان، تخترق الحقوق غير المالية نطاق الأمـة المالية(ْ) عن طريق

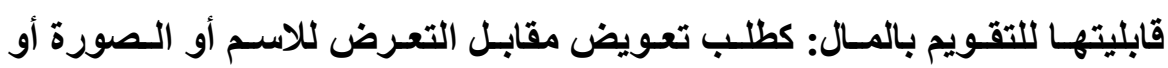

(1) P. Roubier, L'indisponibilité des droits de la personnalité, thèse, Dijon, 1987, n. 291.

(2) D. Berra, le principe de libre disposition des biens en droit civil, Contribution à la notion d'indisponibilité juridique, précité, p. 165.

(3) P. Catala, La transformation du patrimoine dans le droit civil moderne : RTD civ. 1966. n. 25, p. 185 ; A. Seriaux, La notion juridique de patrimoine : RTD civ. 1994, n. 5, p. 801.

(4) V. F. Hage-Chahine, Essai d'une nouvelle classification des droits privés : RTD civ. 1982, n. 4. P. 705.

(5) J. Cl. Civil, art. 1598, Vente, Choses pouvant être vendues, par L. Cadiet, n. 42. 
الثرف، الخ... هكذا تحل قيمة مالية محل قيمـة معنويـة لذلك يمكن لأكثر الحقوق

\section{المتعلقة بالشخصية أن تصبح محلا للالتزام (').}

- بثأن لحقوق الأمـة الماليـة، هنـاك من يأخذ بعين الاعتبـار شخصية صـاحب هذه الحقوق ليعطي قيمة معنوية لقيمتها المالية البحتة، فتصبح هذه الحقوق غير قابلة

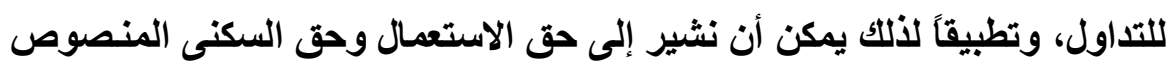
عليهما في المادة هـ 9 من القانون المدني الكويتي (؟).

إن حجم هذا التـاخل المزدوج للحقوق الخارجة عن الأمـة المالية في مجـال قابلية التنازل من جهة وحقوق الأمة المالية في مجال عدم جواز التصرف من جهة أخرى، يُعَدَكبيراحتّى إنه لا يمكن تفادي السؤال حول العلاقة بين مـا يتعلق بالذمـة

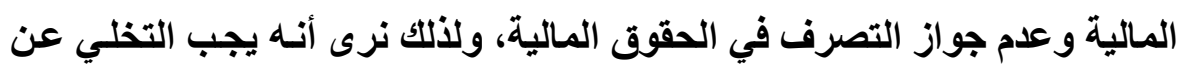
معيار ما يتعلق بالذمة المالية الذي يرجع إليه، لتحديد قابلية الحقوق للتداول أو

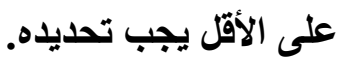

وعلى الرغم من التشبيه التقليدي، والذي غالباً مـا يتأكد، بين التعلق بالذمـة المالية وقابلية الحق للتداول، لماذا لا تتفق الصفتان بانتظام؟ ولماذا نجد استثناعات ملموسةْنظنّ أن الرد يكمن أساساً في كون قابلية التداولتُعذىبالحق نفسه، الذي لـاني هوكما ذكرنـاـ امتياز خارجي، ألا وهو القدرة على التصرف القانوني، في حين أن

(1) G. Ripert, La règle morale dans les obligations civiles, $4^{\mathrm{e}}$ éd., LGDJ, 1949, n. 24.

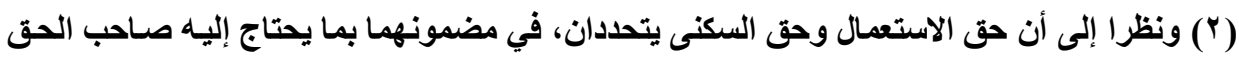

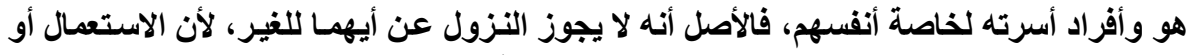

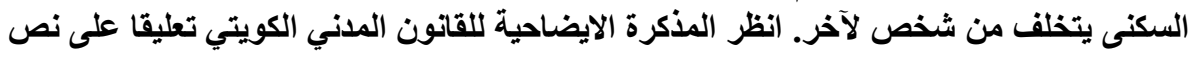


صفة التعلق بالأمة المالية من عدمـه تعتمد على محل هذا الحق، ولذلك لا يمكن وضع هاتين الصفتين في المستوى نفسه: ففي حين ينبع التعلق بالأمة المالية من

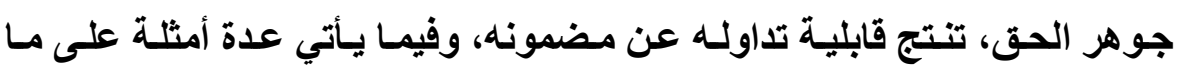

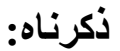

- حق الملكيـة على عقـار هو المثال الأصلـي لحق الأمـة الماليـة بسبب المفهوم

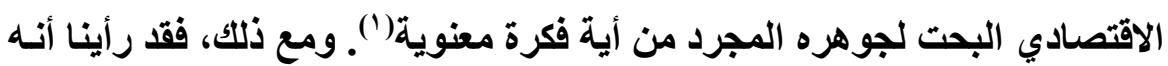
وفق المـادة ه 1 مـن القانون المـدني الكويتي يمكن منـع المالكك من نقل ملكية العقار،والسبب لا يكمن في أي تغيير في جوهر الحق الذي يستمر وصفه بكونـهـ متعلقاً بالأمة المالية، ولكن يرجع السبب إلى الشرط العقدي الذي يمنع المالك من التصرف في ملكه لوجود الباعث القوي.

- إن مضمون دين مالي دائماً ما يكون أداءعً نقدياً من قبل المدين، وهو القيمة المالية بعينها،فكيف لنـا إذاًأن نعلّل عدم قابليته للحوالـة أو عدم جواز التــازل عن دين دين النفقة، التي لها نفس مضمون أيّ دين نقدي آخر، على أسـاس التعلق بالذمـة الماليةٌ لا يكمن التسويغ، مرةَ أخرى، في مضمون الحق ولكن في جوهره(؟). ـ على عكس الحقوق المالية، فالحقوق غير المالية ، مثل حقوق الشخصية، ترتبط شخص صاحبها أو صفاته الأساسية(")، وعليه فإن تحديد كون الحق من الحقوق المالية أو من الحقوق غير المالية يرجع إلى موضوع الحق. ومـع ذلك، فـإن الحد الفاصل بين الحقوق المالية والحقوق غير المالية يكون غير واضح علدما يكون

(1) V. M. Seriaux, La notion juridique de patrimoine, précité, p. 801.

(2) V. A. Sayag, Essai sur le besoin créateur de droit, LGDJ,1969, p. 66.

(3) Ibid., p, 64. 
لعدم جواز التصرف في الحقوق الأولى الصفة المطلةة،أي عدم جواز التصرف بتلك الحقوق المالية بشكل مطلق، في حين أن الحقوق غير المالية هي حقوق لا

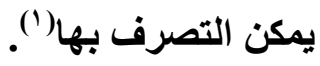

يمكن لنا أن ندرك مما سبق أن الحد الفاصل بين الحقوق القابلة التداول بحرية وتلكا التي لا يمكن أن تكون قابلة للتداول، لا يلتقي مـع الحد الفاصل بين الحقوق المالية والحقوق غير المالية،فإذا كاتت الحقوق الأخيرة لا يمكن تداولها أو التعامل لهل بها أبداً، فلا يمكن دائماً تحويل حقوق الأمـة المالية. فإذاذا أردنـا تقدير صفة قابلية تــاول حقى الأمــة المـاليـة، فـلا يجب النظر إلـى مـضمون الحقى، بـل إلـى كيفيـة ممارسته: فإذا استدعت الممارسة إدخال فكرة من قبيل الحقوق غير المالية، فلا تصبح قابلية التعامل أو التداول بحرية ممكنة(؟).

إن مجـال ممارسـة القدرة القانونيـة في التصرف بحريـة داخل ذمـة الشخص

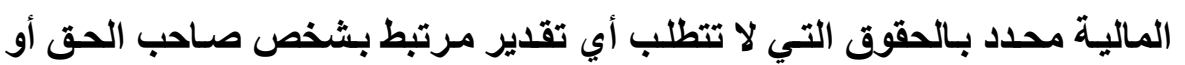
بثخص آخر معين، أي تلك الحقوق التي لها صفة حيادية في مضمونها وجوهرها وطرق ممارستها. إلا أن هذا الشرط اللازم غير كافٍ، ويجب إضافة معيار آخر إلى هذا الشرط الخـاص بالـصفات اللازمسة للحقـوق المطلـوب التصرف فيهـا، وهـو معيارخـارجي يتمثل في كون صـاحب الحق هو الوحيد الذي يمكنه التصرف فيه

(1) V. H. Ph, Visser't Hooft, Les actes de disposition concernant le corp humain. Quelques remarques philosophiques: APD. t. 24, 1979, p. 91.

(2)V. J.L. Aubert, Le droit pour le créancier d'agir en nullité des actes passes par son débiteur : RTD civ. 1969, 692, n. 25. 


\section{ثانيا: العنصر الخارجي: وجود صاحب الحق}

يفترض مفهوم الحق الشخصي وجـود صـاحب حق أو أكثر بمعنى أشـخاص

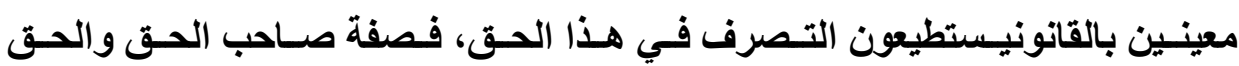
الشخصي مرتبطين بثكل وثيق بالأمة الماليةالتي هي مجموع من الحقوق والالتزامـات للشخص والتي يمكن تقويمها مالياً.

وهكذا،لا يمكن مقارنة صلة صاحب الحق بعلاقة الملكية، بسبب البعد الممتد إلى إنى

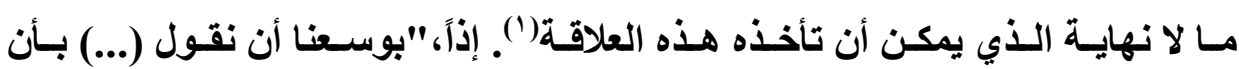

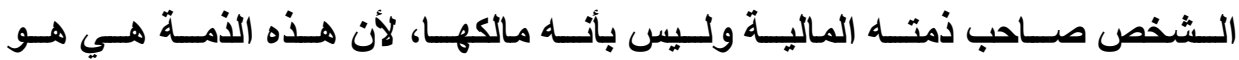

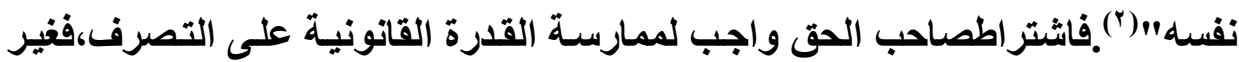
صاحب الحق ليس مخولا بتاتاً بالتصرف، إلا إذا كان الممثل القانوني لصاحب الحق، ولكن في هذه الحالة، لا يمكن الحديث عن ممارسة|لقرة على الاختيار أو حرية الاختيار التي يخولها هذا المفهوم، بل على العكس، إنها قدرة محدة تحديداً مخولا من أجل تتفيذ مصلحة مختلفة عن مصلحة الشخص الأي يقوم بها. واشتراط كون صاحب الحق هو الوحيد الذي يمكنه التصرف لا يمكن الاعتراض عليه أبداً لأنه بليهي. ولكن لنلاحظ -وهذه الملاحظة توضح المبدأ وليست استثناءًء أنـه. يمكن التصرف في حق معلق على شرط مـع العلم بأن هذا الحق سينقل بذات الوصف

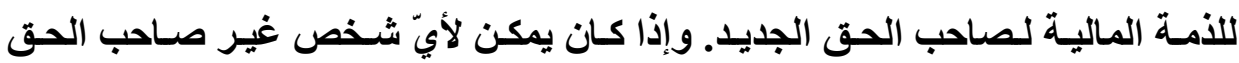
التصرف قانوناً في هذا الحق،فهل يمكن القول بأن هذا الحق غير قابل للتصرف بالنسبة

(1) J. L. Bergel. M. Bruschi et S. Cimamonti, Traite de droit civil- Les biens, LGDJ, 2000, n. 44.

(2) J. Carbonnier, Droit civil, t-3, Les biens, PUF, $19^{\mathrm{e}}$ éd., 2000, n.4. 
لغير صاحبه؟ الإجابة بالتاكيد لا، وقد لاحظنـا أنه "يجب تقدير منـع التصرف في إطار

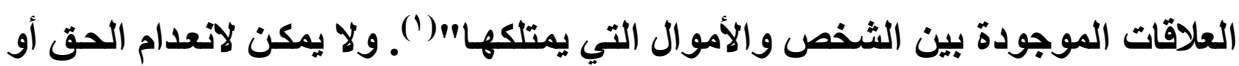
لانعدام القدرة أن يشكلا نوعاً من أنواع المنع منالتصرف، إلا إذا تم تفريغ هذا المفهوم من خصوصيته وهي أن المنع من التصرفيفترض صفة صاحب الحق.

وعليه، نستطيعأن نؤكدأن حرية التصرف القانوني تشكل تعبيراً عن الشخصية، وهي لا تتعلق بجوهر الحقوق ولا بجوهر حق الملكية بالذات، بل يمكن أن تزاول عدداً كبيراً من الحقوق، فما هي هذه الحقوق؟ هذا هو ما نريد تحديده بالتساؤل حول الثروط التي تسمح بـالتعبير عن القدرة القانونية على التصرف. ويمكنــا من الآن -بنظرة معاكسةـ تحديد ذلك فيما يتصلبالثرط العقدي المانع من التصرف. ا ـ يفترض المنع من التصرف أن يكون المدين بـالالتزام هو صـاحب المسال أو الحق الأي أصبح محظور التصرف فيه، إذ إنه الوحيد الذي يستطيع التصرف قانونـاً في المال. بيد أنّا قـ رأينـا أن أي شكل من أشكال المنـع من التصرف الموجهة لغير صاحب الحق لا تشكل حظر آللتصرف بالمعنى الذي نقصده من هذا التعبير. r ـ إن المنع التعاقدي من التصرف، وبسبب مصدره التعاقدي نفسه، لا يمكن تصوره إلا في مجال حقوق قابلة للتعامل أو للتداول وأصبحت غير قابلة للتصرف بإرادة الأطراف(†). وعليه، فإن اهتمامنـا بتحديد الحقوق القابلـة للتداول بحريـة أو لا، يسمح لنا أن نستبعد بعض أشكال منع التصرف من الحقوق، من خلال دراستنا هذه، أي تلك المتعلقة بالحق نفسه وبعدم قابليته للتصرف، وأكبر مثال على ذلك هن

(1) D. Berra, thèse précitée, p. 160.

(2) V. R. Marty in De l'indisponibilité conventionnelle des biens ( $1^{\mathrm{e}}$ partie), Petites affiches 21 nov. 2000, 4. n. 3. 
هو منع التصرف في جسم الإنسان، وهو منع مطلق. ولكن يمكنتا أيضاً إضـافة

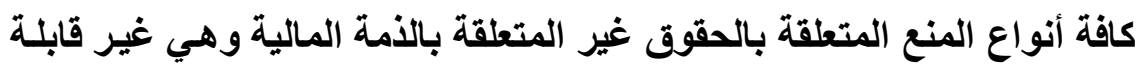

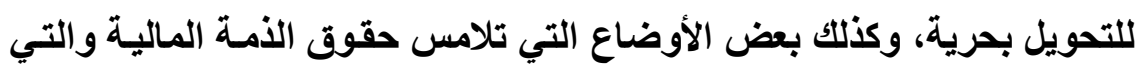

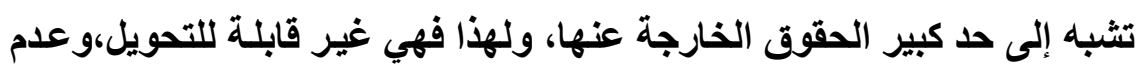

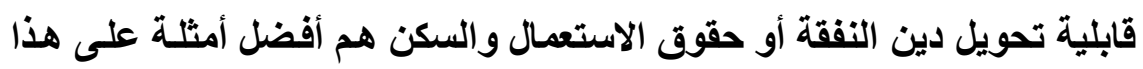

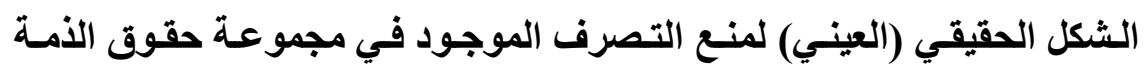

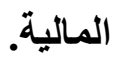

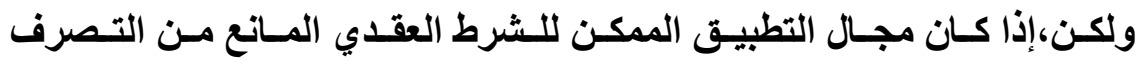

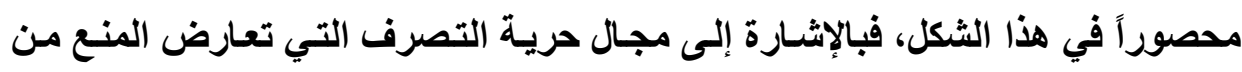

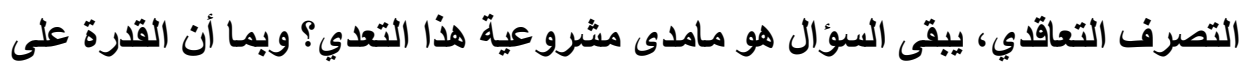

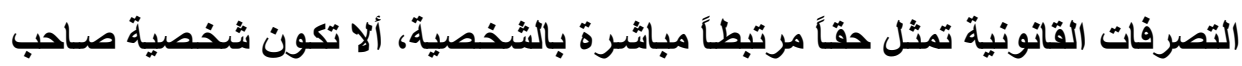

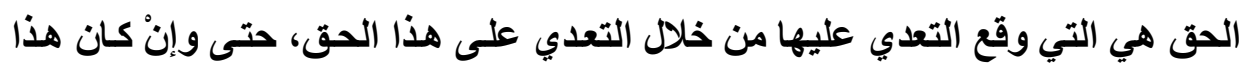

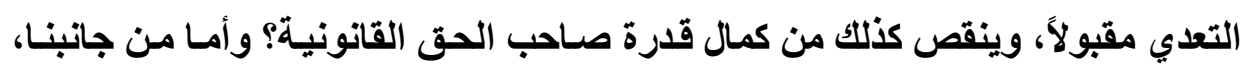

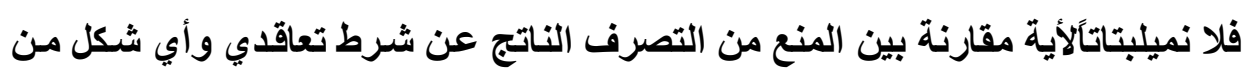

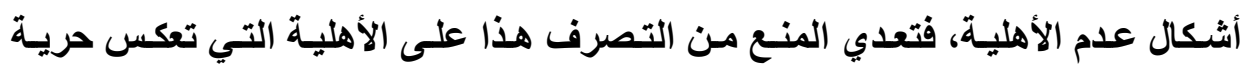

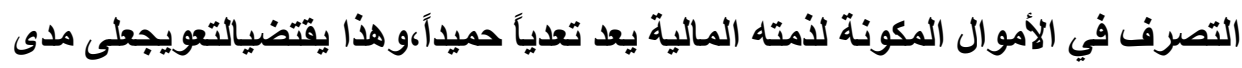

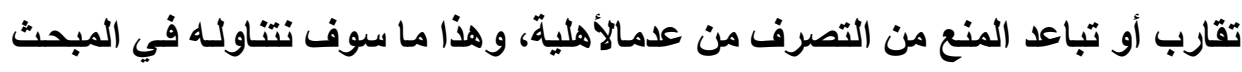




\section{الببمث الثاني \\ هدى علاقة المنع هن التصرفبهدم الأهلية}

إن المنع من التصرف في الحق يمس القدرة القانونية على التصرف وهي إحدى

الخصائص الأساسية للشخصية القانونية، وهذا المنع قد يؤدي إلى التقارب من حالة

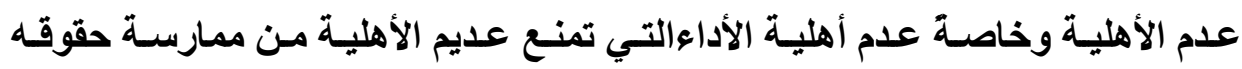
والمطالبة بها'(')، للك فإن أي شكل من أشكال منع التصرف المطلق الناشسئ عن العقد منوع منعاً مطلقا.

ومسن هــا المنطلق يتبـادر إلـى الـــهن التـساؤل الآتـي: هـل يمثـل المنـع مـن التصرفشكلا من أشكال عدم الأهلية ؟ بلالعكس،نرى أنه على الرغم من التقارب الذي

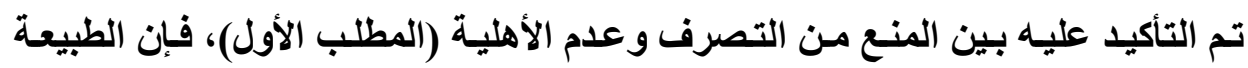
القانونية لهذين النظامين مختلفة تماماً (المطلب الثاني).

\section{الإطاب الأول \\ مدى التقارب بين المنع هن التصرفوعدم الأهلية}

إن النظرية التي حاولت في نهاية القرن التاسع عشر التسويغ القضائي لشروط عدم جـواز التصرف قدمت مـن بـين الافتراضـات فكرة إمكانيـة أن يكون المنـع مـن

(1) J. Carbonnier, Droit civil, t-1- Les personnes, précité, p. 99. 
التصرف شكلاً تقليايًا لعدم الأهلية ـحتى ولو أنه تم استبعاد هذه الفكرة فور صدورها(') - بسبب الصفة القانونية البحتة المرتبطة بحالات عدم الأهلية، فهي تترجم مع ذلك قوة الجذب الموجودة بين النظامين، نقصد هنا نظام المنع من التصرف ونظام عدم الأهلية. وهذه الجاذبية مستمدةمن عدة نـواح: أولاً، قد أكدنا على أن الأهلية القانونية وحرية التصرف تغتذيان على المفاهيم نفسها التي تدور حول الثخصية والحريـة التي توحي بها الثخصية القانونية، هذا من جهة، ومن جهة أخرى، يجب الاعتراف بأن تفسير شروط عدم جواز التصرف وفقا لمفهوم عدم الأهلية يتفق مـع الجزاء المقرر عند التصرف بما يخالف شرط عدم التصرف، من خلال إمكانية إبطال التصرف،وميع ذللك، يبدو لنا أن التثابه الأكثر وضوحاً بين عدم الأهلية والمنع من التصرف يظهر في الهدف الذي يتبعه هذان النظامان. يميز القانون المدني بين حالات عدم القدرة القانونية على التصرف، حسب الهـف المخصص لكل حالة، فنستخدم مصطلح الأهلية لوصف تلك الحالة التي تهدف

(1) ينبغي الإثارة هنا إلى أن بعض الفقه الفرنسي كان رافضاـ خلال القرن التاسع عشر وبداية القرن

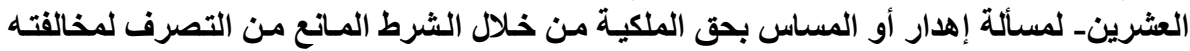

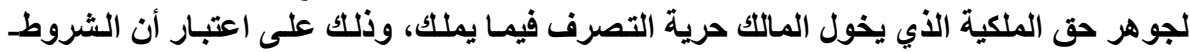

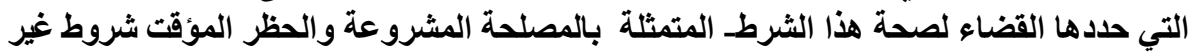

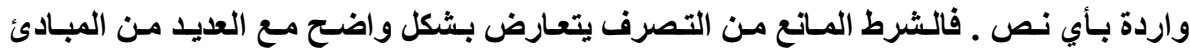

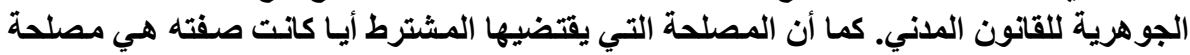

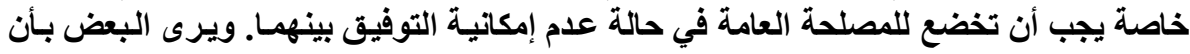
ذللك الثرط مـا هو الا باعث مفسر

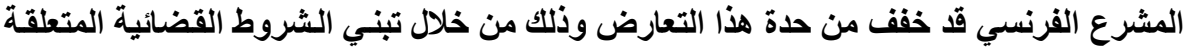

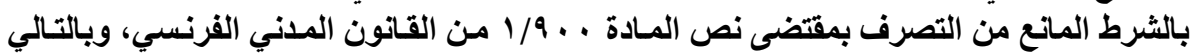

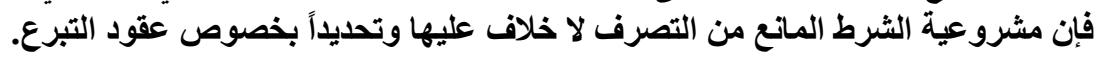

V.L. Josserand, Les mobiles dans les actes juridiques du droit privé, Dalloz, précité, n. 208. 
أساساً إلى حماية عديمالأهلية أو ناقصها من ضعف إرادته، وهناك المنع القانوني -أي

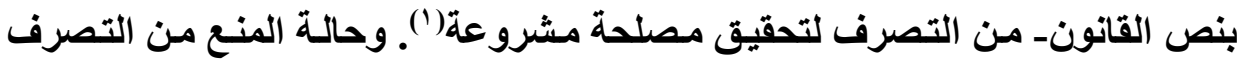

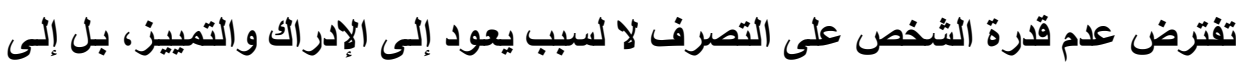

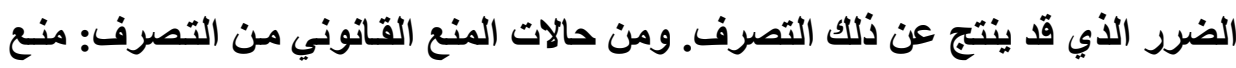

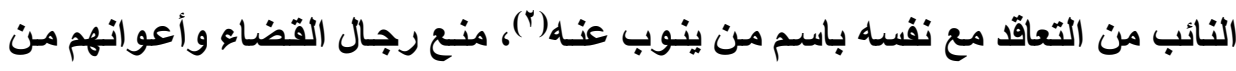

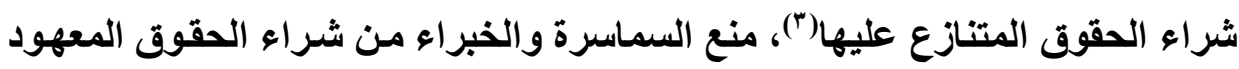

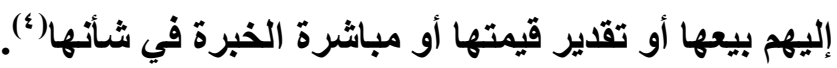

أما ما يتعلق بالمنع من التصرف تعاقديا،أي عن طريق الاتفاق على هذا المنع، نلاحظ أن دراسـة شروطه تظهر انقساماً ممـاثلاً، فهي مستوحاة مرة من أجل حمايـة

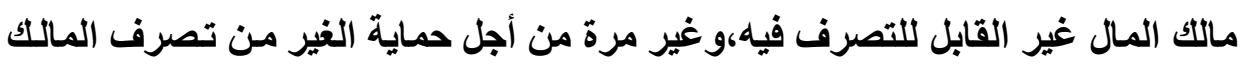

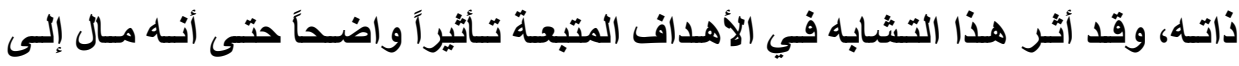

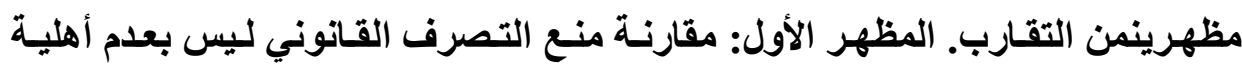

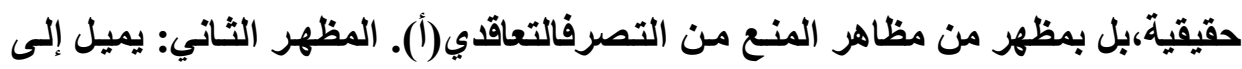
دمج حالات المنع من التصرف التي تهذف إلى حماية صـاحب الحق أو المـال المحظور

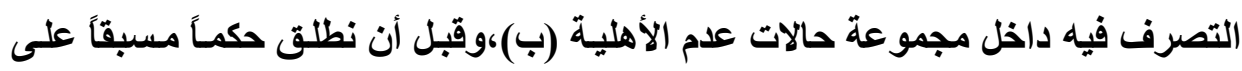

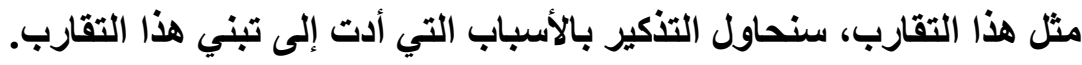

(1) عبد الرزاق السنهوري، الموجز في النظرية العامة للالتزامات في القانون المدني، المجمع العلمي

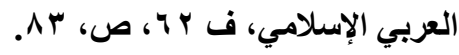

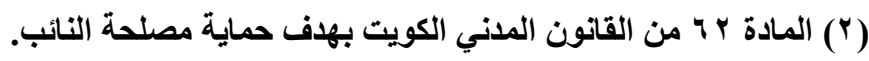

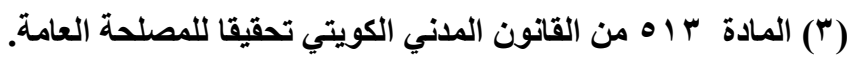
(؛) المادة ؛ ؛ اه من القانون المدني الكويتي. 


\section{أولا:المنع هن التصرف قانونا واتفاقا}

التمييز بين المنع من التصرف بناء على نص قانوني والمنع من التصرف بنـاء

على اتفاق بين أطر افه من أهم الموضوعات المتعلقة بالأهلية (')، ورغم أهميته إلا أن ذلك لم يمنع من نقد هذه التفرقة، بل أن بعض الفقهه اعترضوا عليه بشدة: فهنـاك من يرى أن الأهلية هي التي تُكوّن مفهومـاً قانونياً حقيقيًَ(٪)، أمـا بقيـة أنواع عدم الأهلية الأخرى فتكون مجموعة من عناصر مختلفة،فكيف يمكن إذاً وصف هذه المجموعة ووضـعها مـن بين أنـواع عدم الأهليـة؟ لا يتردد الفقهـه في تشبيهها بحالـة المنـع مـن التصرف لاعتقاده أن الفرق بين الاثنين "غير ملموس"(").

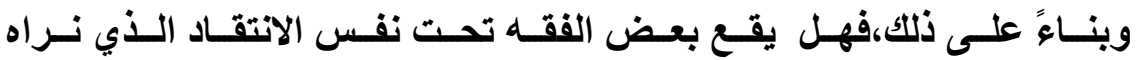

مبرراًوالموجه إلى التصنيف التقليدي الأي يؤكد على الهـف من عدم الأهلية أكثر ممـا يؤكد على النظام القـانوني للأهليةّ؟ فبإذا كـان تعريف عدم الأهليـة مبنياً على هدف الحماية التي يتبعه بالضرورة نظام الأهلية كما رأينا من قبل، فإذا اعتمدنا هذا التعريف، يجب أن نتساعل أيضاً عن اندماج بعض أنواع المنع من التصرف التي تميل إلى حمايـة بعض الأشخاص من ضعف إرادتهم المفترضـة في مجموعة عدم الأهلية المنحصرة

R. Houin, les incapacités: RTD civ. 1947, p. 383.

R. Houin,lesincapacités, précité, p. 386.

Ibid., p. 386. 


\section{ثانيا: المنع هن التصرف والأهلية}

يظهر التشـابه بين مفهوم الأهلية والمنـع من التصرف من خلال الغاية التي

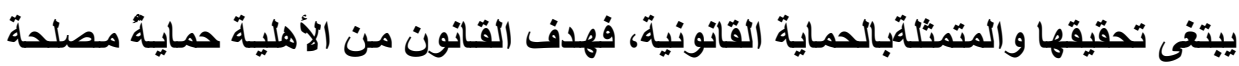
عديم الأهليـة أو ناقصها لضـف إرادتـه أو انعدامها، ومـن أهداف الشرط المـانع مـن التصرف حمايـة مصلحة المالك ( المتصرف لـه) صساحب المسال غير القابل للتصرف فيـه(')،كمـا أندعوى المطالبـة بإبطال التصرف القـانوني بالنسبة للأهليـة أو المنـع مـن التصرف، تكون فقط لمن تقرر الإبطال لمصلحته أي المنتفع من الحماية.

إن حمايـة صـاحب المـال مـن خـلال منعـهـ مـن التصرف في مـالهيكون نتيجـة اعتبارات خاصة بشخصية صاحب المال أو الحق، وأن هذه الصفة بالذات هي التي قد تبين عدم أهليته للتصرف، ولكن عدم جواز التصرف، المقصود به التعرض للقدرة على التصرف، وهي ميزة باطنية للشخصية، تأخذ دائمساً بعين الاعتبار، بطريقة أو بأخرى،

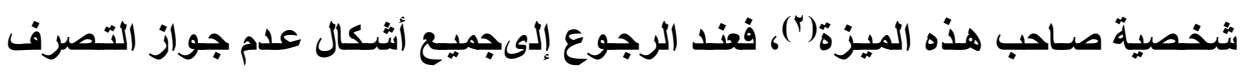
المنصوص عليها في صـالح الغير أو للمصالحة العامـة، وسنستطيع دائمساً تفسيرها شروطاً تبين مدىالحذر مـن المالك نفسه والذي يخشى أن يمس بالمـصلحة المـراد

R. Houin, précité, n. 391; A. Tissier, note ss Cass. req., 23 mars 1903 : S. 1904, I, p. 225.

A. Wager, La clause d'inaliénabilitédans les donations et les legs, RTD civ, 1907, p. 345.

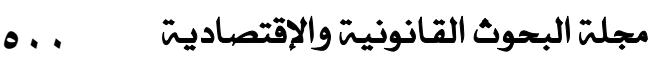


لقد أثرنا سابقا إلى أن عدم جواز التصرف منقسم بنفس طريقة عدم الأهلية، ونستطيع تأكيد ذلك من جديد هنا: إذا كان هناك حالات عدم أهلية مبنية على حماية التهاية

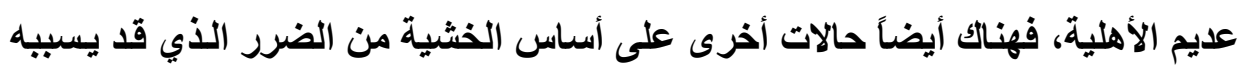

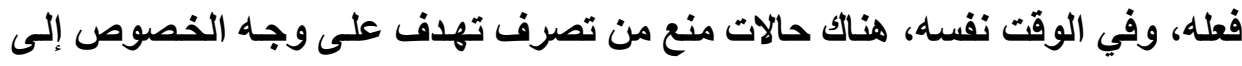
الحفاظ على مصلحة صاحب المال، في حين أن هناك حالات أخرى تهاف قبل كل شيء

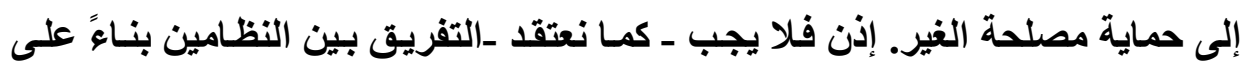

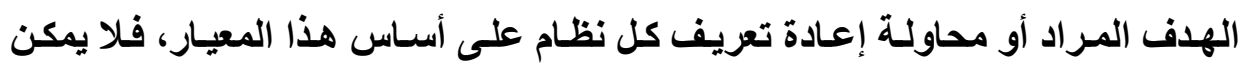

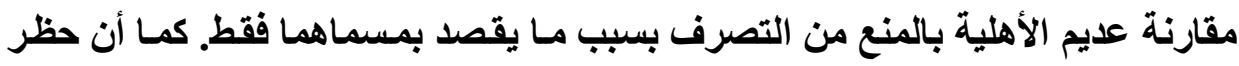
التصرف لا يمكن أن يشكل مظهراً من مظاهر عدم الأهلية فقط لأنه يهدف إلى حماية صاحب المال غير القابل للتصرف. في الواقع، يجب البحث عن الفرق بين النظامين ليس في القصد المخول لكل منهما، بل في صفاتهما الخاصة التي تظهر فروقئ التهاً واضحة بينهما.

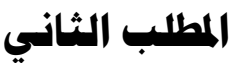

\section{هدى التباعدبين المنع من التصرف وعدم الأهلية}

لقد ذكرنا أن هناك تثابهاً كبيراً بين المنع من التصرف وعدم الأهلية: فالاثنان

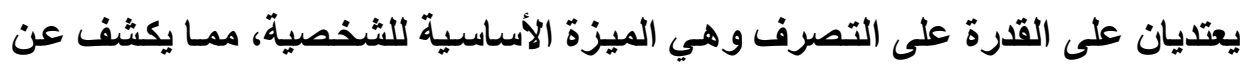
طبيعة قانونية متثابهة للغاية ساهمت كثيراً في التقارب بينهما، إلا أن ذلك مـاز ال محل

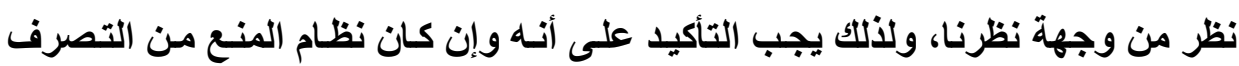

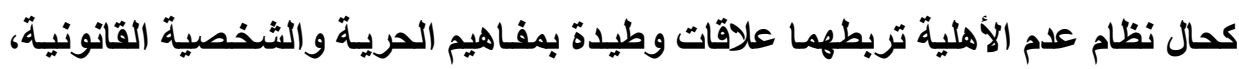
إلا أن الأساس القانوني في كل نظام مختلف تماماً عن الآخر. 
إن التحديد الـقيق للمنع من التصرف، المختلف عن أي نـوع من أنواع عدم الأهلية، لا يمثل مجرد فرق بسيط في الدرجة بين النظامين، بـل إنـه فرق أساسي يبيّن وحده صلاحية المنع من التصرف التعاقدي(أولا) ويمنع مقارنته بعدم الأهلية (ثانيا).

\section{أولا: المنع هن التصرف همدد الاضشمون}

يتقق معظم الفقه على أن أحد الصفات المميزة للمنع من التصرف هو التحديد

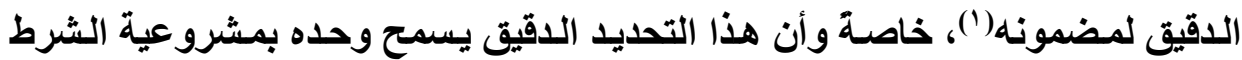
المانع من التصرف، نظرا لمـا يتضمنه المنع من التصرف من اعتداء و إهدار لسلطة

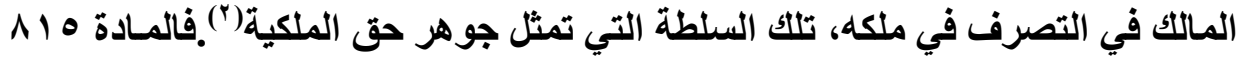
من القانون المدني الكويتي تشترط أن يكون المنع من التصرف مبنياً على باعث قوي أي تتيح مصلحة جدية مما يترتب على ذلك عدم الاعتداد بأي غرض يسعى المشترط

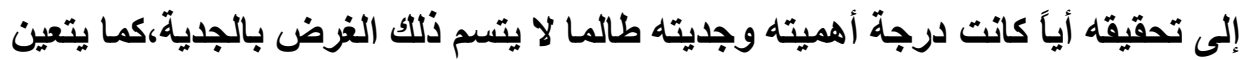

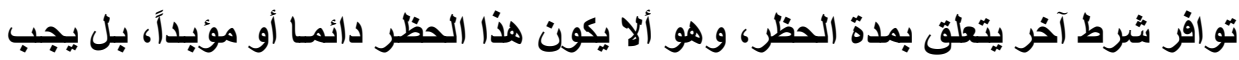

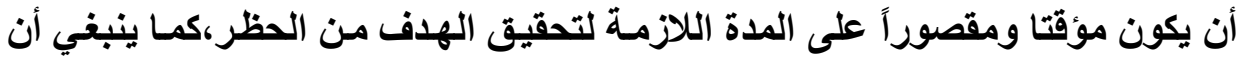

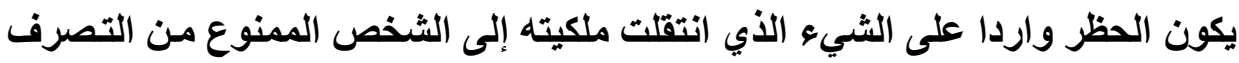
بمقتضى تصرف ناقل للملكية("). ولكن يجب أن يستثنى من ذلك التنازل عن الحق، فهو

V. Y. Guyon, Le droit de regard du créancier sur le patrimoine et l'activité de son débiteurconsidérécommesûreté : Colloque Deauville, RJ com. 1982, n, spécial, p. 132.

(r) إبراهيم أبو الليل، الحقوق العينية الأصلية، حق الملكية، مجلس النشر العلمي، جامعة الكويت،

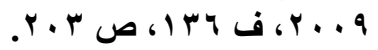

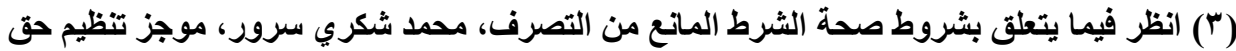

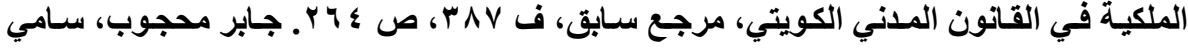

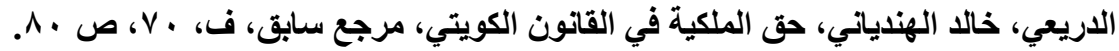


بالفعل شكل موستَع من المنع من التصرف، وهنـا يمكن تبرير مقارنـة التنـازل عن الحق بالمنع من التصرف، فالمراد هو تخصيص الأموال لصالح دائني المدين أكثر من الوقئ مناية

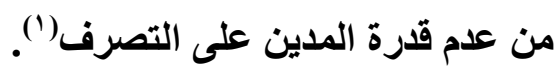

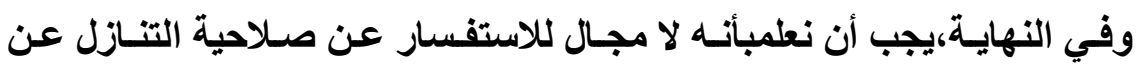
الحق باعتباره إجراء منصوص عليه في القانون صراحة. ولكن نستطيع أن نؤكد على

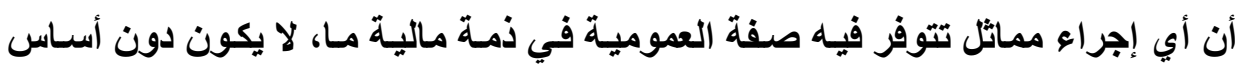

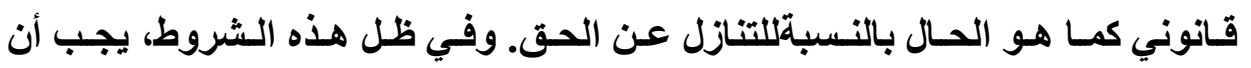

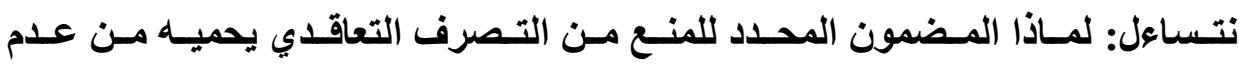

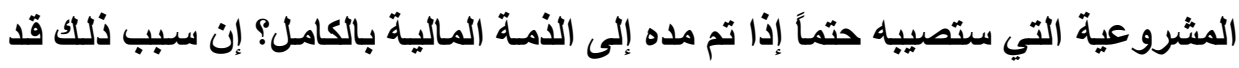

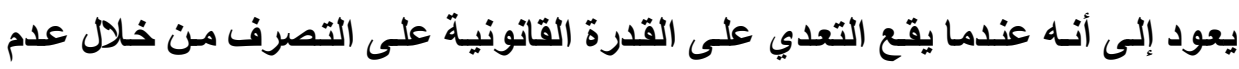

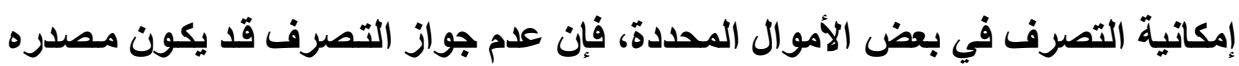

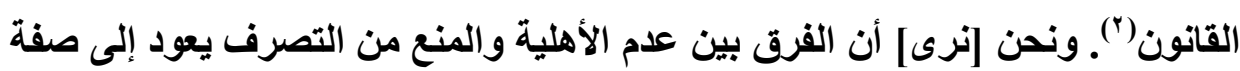

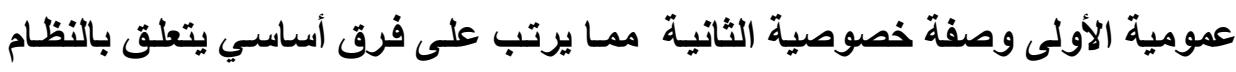
القانوني لكل منهما.

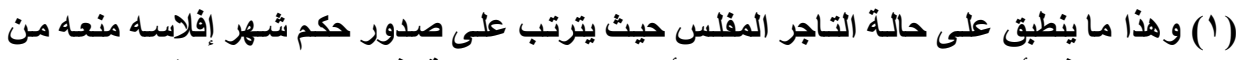

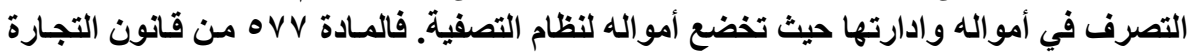

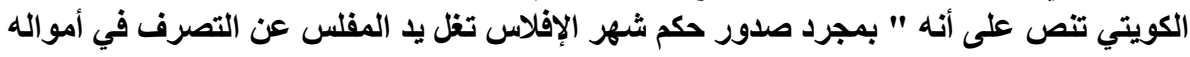

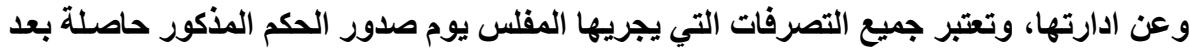

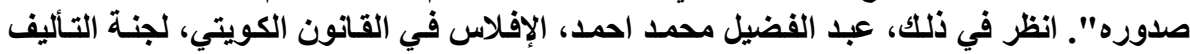

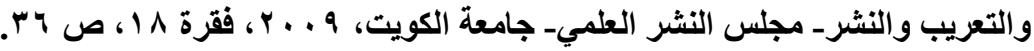

(2) " Lorsque l'incapacité de protection est limite à certains biens, elle peut avoir une origine contractuelle. Il n'en résulte pas une grave atteinte à la liberté individuelle, car l'indisponibilité conventionnelle doit se justifier un intérêt légitime et elle doit être temporaire". R. Houin, précité, p. 391. 


\section{ثانيا : هبدأ التخصيص جوهر المنع هن التصرف}

لا نريد هنا مجرد إثبات أن المنع من التصرف يمس مالاً أو حقاً معينًا فحسب في

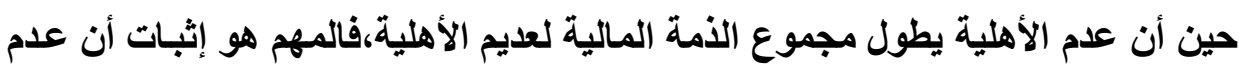
الأهليـةيعارض فكرة أنـه يمس فقط بعض الأمـوال بعينهـا داخل الأمـة الماليـة لعديم

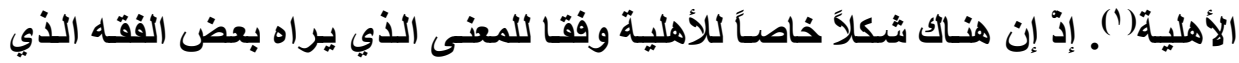
يكيف المنع من التصرفبأنه "ليس إلا عدم أهلية معينة لامتلاك بعض الأموال، أي عدم

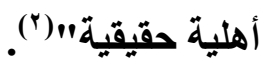

بالتأكيد، نحن لا نريـا إنكار أن مفهوم عدم الأهلية الخاصـة واقع في قانونتسا، ولكن ما هو هذا الواقع على وجه التحديد؟ وبمصطلح عدم الأهلية الخاصـة، نتصور الحـالتين الآتيتين: توصف عدم الأهليـة: بالخاصـة؛ إمـا لأنها تمنـع عديم الأهلية مـن التعاقد مع بعض الأشخاص، وإمـا لأنها تحظر عقوداً معينة على عديم الأهلية. ونرى أنهذا التحديد في الحالتين-لا يمس-بأي حال من الأحوالـ الحق المحظور التصرف فيه، سواءً كان مالاً أو حقاً معيناً، وهذا طبيعي إذا رأينا أن عدم الأهلية، على الأقل من ناحية الذمة المالية، لا تهتم بالقدرة على التصرف أو التعاقد إلا بالنظر إلى الافتقار الأي قد ينتج عن ممارسة هاتين القدرتين سواعً في الأمة المالية لعديم الأهلية نفسه أو في الأمة المالية للغير.ففي القانون المدني الفرنسي بقي البيع بين الزوجين ممنوعاً مدةً طويلة لأن المشرع كان يرى في مثل هذا البيع خطورةلافتقار حقيقي لذمة أحد الزوجين

D. Berra, thèse précitée, p. 970.

R. Houin, précité, p. 401. 
المالية لصالح الآخر. وهذه المشكلة الموجودة في نظام عدم الأهلية كله. ونعتقد أنتـا يجب أن نبحث في هذه المشكلة عن وحدة هذا النظام بغض النظر عن الأشكال المختلفة

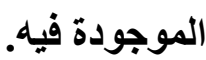

فإذا ما نظرنا إلى حالات المنع من التصرف أياً كان مصدرها، يجب أن نلاحظ أن السبب المـؤدي إلى مسروعيتها مختلف تمامساً: فالهـف ليس حمايـة الأمسة الماليـة للشخص الذي يطاله المنع أو الذمة المالية للغير من التصرف القانوني،فحظر التصرف يهدف إلى الحفاظ على حث أو مال معين داخل الأمة المالية لصاحبه، فهو يقوم بوظيفة تخصيص لا يعرفها نظام الأهلية. قد يعترضبعضهم على القول بـأن التـــازل عن الحق هو نـوع مـن المنـع مـن التصرف الذي قد يمس الذمة المالية بأكملها، وأن هذا الاستثناء، لأهميته، قد يكسر هذا المبدأ، ولكنتـا سبق وأن قررنـا لمـاذا لا نرى ذلتك: حتى وإن طسال ذمـة مالية بأكملها، بفضل استثناء قانوني لقواعد حالات المنع من التصرف العادية، فالتنازل عن الحق مـا زال يقوم بوظيفة تخصيصية لأنها الأمـة المالية بأكملها التي يتم تخصيصها لصالح الـدائنين عـن طريـق الحجـز الكامـل على الأمـوال. وهكــا فـإن التـــازل عـن الحـق لا يُعدّاستثناء من القاعدة العامة بل تأكيداً عليها في فرضية معينة. وهكذا، باسـتطاعتنا أن نـرى أن الصفة المحـدة الخاصـة بجـوهر المنـع مـن التصرف لا ثُعَّ بالنسبة لحالات عدم الأهلية مجرد فرق في درجة خطورة التعدي على القدرة على التصرف القانوني، بلبها تفعيل طريقتين قانونيتين مختلفتين تمامساً، الأولى تقوم بتخصيص مال أو حق والأخرى لا تقوم بذلك، وعليه نستطيع رسم حد فاصل بين

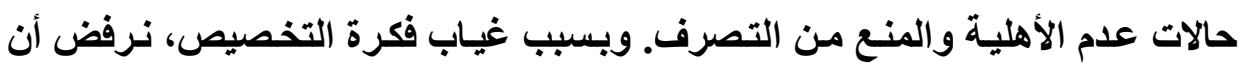
يوصف المنع القديم للبيع بين الزوجين بحظر تصرف، في حين أنهه شكل من أشكال 
عدم الأهلية، وبـالعكس، تعتبر المـادة هـ9 من القـانون المدني الكويتي، بتخصيصها فيمـا يتعلق بحق الاستعمال وحق السكنى، حالة حظر تصرف، لا إنقاصـاً من القدرة القانونية لصاحب الحق في الاستعمال أو السكن.

وهكذا،لا يسمح "مبدأ التخصيص"(')، جوهر المنع من التصرف، فقط بالتفرقة

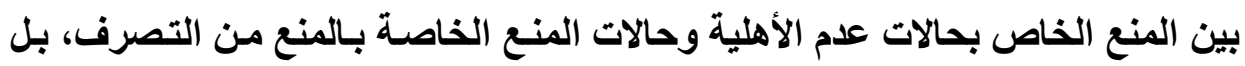
يوضح ويعلّ الفروق الأخرى الموجودة بين النظامين. وعليه، فإن المنـع من التصرف لا يترك أية مساحة بأي حال من الأحوال للنيابة القاتونيـة كمـا هو الحسال بالنسبة لعديم

الأهلية فيما يتعلق بذمته المالية(ب).

إن السبب في أن المنع من التصرف لا يعطي أية إمكانية للنيابة القانونية لتمثيل صاحب المال أو الحق غير القابل للتصرف يعودإلى فكرة التخصيص التي ينطوي عليها هذا النظـام، فهـف المنـع مـن التصرف هو الحفـاظ على المـال أو الحق داخل الأمـة المالية. فكيف يمكن ضمان تحقيق مثل هذا الهـف إلا بإقصاء أية فكرة نيابـة قانونية أو قضائية لصاحب الحق؟ الحل الوحيد هو رفع المنع من قبل الشخص الذي يريد حظر التصرف، إما مسبقاً من خلال التصريح أو لاحقاً من خلال الإقرار بالتصرف. وللسبب ذاته الذي يستبعد بـه المنـع من التصرف النيابـة لتمثيل صساحب المـال غير القابل للتصرف فيه، فإن غياب كل تخصيص هو الذي يسمح بـالعكس لنيابة عديم

R. Marty, De l'indisponibilité conventionnelle de biens (suite et fin): Petites affiches 22 nov. 2000, 8, $\mathbf{n}^{0} 15$.

D. Berra, thèse précitée, p. 969. 
الأهلية، فبما أن عدم الأهلية تهدف إلى تفـادي المخـاطر التي قد تنتج عن نشاط عديم الأهلية ضده أو ضد الغير أو حدّها، فإن من أفضل الوسـائل لتفـادي هذا الخطر أو حدّه

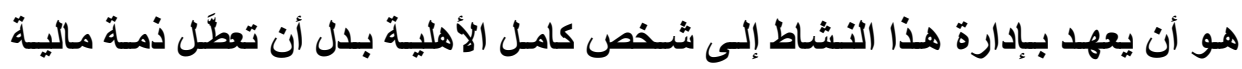
مفروض حمايتها والمحافظة عليها. ولكن ألا يمكن تفسير التمثيل الذي يسمح بـه هذا النظام فقط بأن " عدم الأهلية بمعناهـا الواسـع تظهر كعقبة استثنائية مبنية على صفة خاصة بشخص صاحب الحق"، وأن أفضل طريقة إذاً لإزاحة هذه العقبـة هي استبدال صاحب الحق بشخص آخر يمارس صلاحياته('). لقد وضحنا من قبل وجهة نظرنـا بـأن هذا التفسير غير كاف، فالمنع من التصرف يأخذ أيضاً بعين الاعتبار صفاتِ شخص صاحب الحق، ويحتوي على مسوّغاتٍ مماثلة، ما بين حماية وحذر، لتلك الموجودة في عدم الأهلية، ولكن، وهنا يكمن الفرق المهم، إن أخذ الصفات الشخصية في الاعتبار يرجع إلى تحقيق هدف محدد، ألاوهو الحفاظ على مال أو حق معين داخل الأمة المالية لصاحبه.

R. Houin, précité, p. 385. 


\section{الخاتمة}

في نهاية هذا البحث، يتبن لنا أن القدرة القانونية على التصرف ما هي إلا تعبير عن الثخصية القانونية، فهي لا تتعلق بجوهر الحقوق، ولا بجوهر حق الملكية بالذات، بل إنها تزاول على عدد كبير من الحقوق. بالمقابل، يقوم نظام المنع من التصرف دائمساً بوظيفة تخصيص مال أو مجموعة أموال محددة تماماً لا يجوز التصرف فيها ، في حين تهتم عدم الأهلية بكامل الأمـة المالية للشخص الذي تريـا حمايته أو حمايـة الغير من تصرفاته، ولقد وضــت لنـا هذه التفرقة التفسير المنطقي لكون أحد الأطراف أهلا للتعاقد والآخر غير أهل لذلك، إذ لا يكمن التفسير في تقدير مدى خطورة التعدي على القدرة القانونية على التصرف، لذلك فإن أي تعهل بعدم جواز التصرف لصالح الغير في جميع الأموال التي تثكل الأمة المالية، يعتبر من التصرفات غير الجائرة، وهذا خلاف الثرط الذي يضع قيدا على مـال محدد بعدم جواز التصرف فيه. ولنلكك فإن صـلاحية المنع من التصرف التعاقدي تكمن في التحديد الدقيق لمضمونهخاصة وأن هذا التحديد يسمح وحده بمشروعية الشرط المـانع مـن التصرف، نظرا لمسا يتضمنه المنع مـن التصرف من اعتداء وإهدار لسلطة المالك في التصرف في ملكه، تلك السلطة التي تمثل جوهر حق الملكية، وعليه فإن الفرق بين عدم الأهلية والمنـع من التصرف يعود إلى عمومية المـال في الأمـة المالية لعديم الأهلية من ناحية، وخصوصية المـال بالنسبة

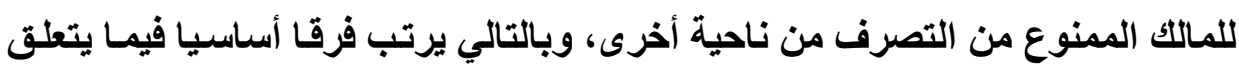
بالنظام القانوني لكل منهما.

كمـا أن صـلاحية المنـع من التصرف قد تكمن في المبررات التـي تعود لبعض

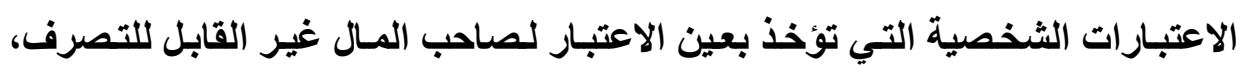
ولذلك فإنمبدأ التخصيص باعتباره جوهر المنـع من التصرف يعتبر السبب الرئيسي 
لصحة المنـع مـن التصرف، إذ إن نظـام المنـع مـن التصرف يهتم بـالأموال أكثر مـن الاعتبارات الشخصية للأشخاص. وهكذا فإن المراد بالمنع من التصرف هو الحفاظ على الأموال داخل الأمة المالية لصاحبها، ومن ثم إن هذا النظام القانوني للمنع من التصرف هن فئه مختلف تماماً عن نظام عدم الأهلية، وهو مـا يفسر ويبرر الاختلاف الخـاص بكل نظام ومدى التعدي على القدرة القانونية على التصرف. 


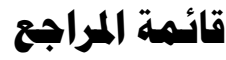

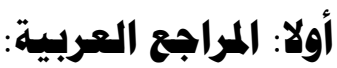

- إبراهيم أبو الليل، الحقوق العينية الأصلية، حق الملكية، مجلس النشر العلمي،

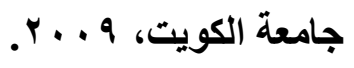

- إبـراهيم الدسـوقي أبـو الليـل، نظريـة الالتززام (1 ) المـصادر الإراديـة للالتزام-

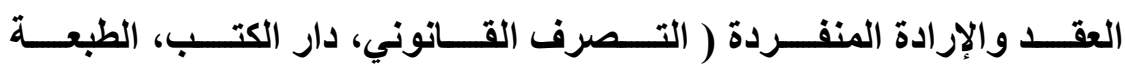

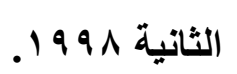

ـ جابر محجوب، سامي الاريعي، خالد الهندياني، حق الملكية قي القانون الكويتي،

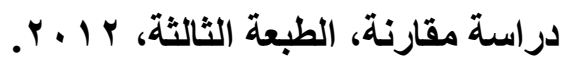

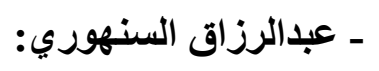

الوسيط في شرح القـانون المـني : حق الملكيـة، المجلد الثامن، منشورات

$$
\text { الحلبي الحقوقية، طبعة و . . . r، بيروت. }
$$

ـ الموجز في النظرية العامة للالتزامات في القانون المدني، المجمع العلمي العربي

$$
\text { الإسلامي، بدون تاريخ طبعة. }
$$

ـ عبد الفضيل محمد احمد، الإفلاس في القانون الكويتي، لجنة التأليف والتعريب

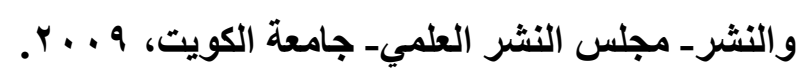


د/ خالد عطشان الظفيرى و د/ مرضى عبيد العياش

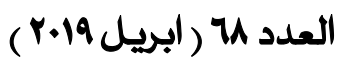

ـ ليلى عبــالله سـعيد، دور الإرادة في تقييـد حـق الملكيـة، مجلـة الحقوقجامعـة

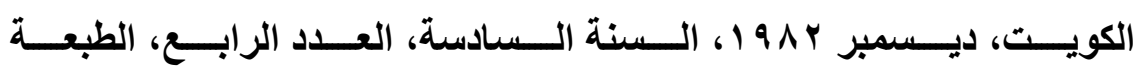

الثانية.

ـ محمد شكري سـرور، مـوجز تنظيم حق الملكيـة في القـانون المـدني الكويتي،

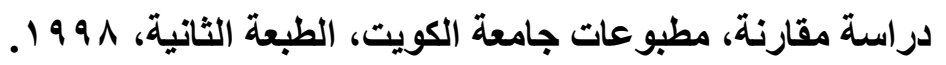

ثانيا: المراجع الفرنسية:

\section{- J.L. Aubert :}

- Le droit de disposer de l'immeuble, in Etude Flour, Defrénois, 1979, n. 2.

- Le droit pour le créancier d'agir en nullité des actes passes par son débiteur : RTD civ. 1969, 692, n. 25.

- Ch. Aubry et Ch. Rau, Cour de droit civil francais, t-3, 4e éd., Paris 1869, n⿳0 190.

- J. L. Bergel. M. Bruschi et S. Cimamonti, Traite de droit civil- Les biens, LGDJ, 2000, n. 44.

- D. Berra, Le principe de libre disposition des biens en droit civil, Contribution à la notion d'indisponibilité juridique, thèse, Nancy, 1969, ler vol. 
- R. Bonnard, Les droits publics subjectifs des administrés. RD pub. 1932, p. 714.

- L. Cadiet, J. Cl. Civil, art. 1598, Vente, Choses pouvant être vendues, n. 42 .

\section{- J. Carbonnier :}

- Droit civil, t-1- les personnes, PUf, $21^{\mathrm{e}}$ éd., 2000,

- Droit civil, t-3, Les biens, PUF, $19^{\mathrm{e}}$ éd., 2000, n.4.

- Droit civil, Introduction, PUF, $23^{\mathrm{e}}$ éd., 1999, n. 184.

- H. Capitant, Sur l'abus des droits: RTD civ. 1982.

- P. Catala, La transformation du patrimoine dans le droit civil moderne : RTD civ. 1966. n. 25.

- A. Chéron, La jurisprudence sur les clauses d'inaliénabilité : RTD civ. 1906.

- E. Gaillard, La notion de pouvoir en droit privé, Economica, $1983, n^{0} 64$.

- S. Ginossar, Droit reel, propriété et créance- Elaboration d'un systéme rationnel des droits patrimoniaux, LGDJ, 1960. 
- P. Guiho, Les actes de disposition sur la chose d'autrui : RTD civ. 1054, 1.

- Y. Guyon, Le droit de regard du créancier sur le patrimoine et l'activité de son débiteur considéré comme sûreté : Colloque Deauville, RJ com. 1982, n, spécial.

- F. Hage-Chahine, Essai d'une nouvelle classification des droits privés : RTD civ. 1982, n. 4.

- R. Houin, les incapacités : RTD civ. 1947.

\section{- L. Josserand :}

- Cour de droit civil positif français, t-1, Sirey, 2 ed., 1932, n. 1850.

- Les mobiles dans les actes juridiques du droit privé, Dalloz, 1928, n. 208.

- H., Léon et J. Mazeaud, Leçons de droit civil, t-2, vol. 1Obligation : théorie générale, Montchrestien, 9 éd. Par F. Chabas, 1998, n. 231.

- R. Marty in De l'indisponibilité conventionnelle des biens $\left(1^{\mathrm{e}}\right.$ partie), Petites affiches 21 nov. 2000, 4. n. 3. 
- A. Piedelievre, Promesse unilatérale de vente immobilière et prenotation : Defrenois 1975, a. 30960.

- M. Planiol, Traité élémentaire de droit civil, t-1, LGDJ, $6^{\mathrm{e}}$ éd., 1911.

- G. Ripert, La règle morale dans les obligations civiles, $4^{\mathrm{e}}$ éd., LGDJ, 1949, n. 24.

- Rouast, Les droits discrétionnaires et les droits contrôles : RTD civ. 1944, n. 4.

- P. Roubier, L'indisponibilité des droits de la personnalité, thèse, Dijon, 1987, n. 291.

- P. Roubier, Les prérogatives juridique : APD 1960.

- Y. Le Roux, Des prohibitions d'aliéner insérées dans les contrat et testaments, thèse, Rennes, 1930.

- A. Sayag, Essai sur le besoin créateur de droit, LGDJ, 1969.

- A. Seriaux, La notion juridique de patrimoine : RTD civ. 1994, n. 5.

- A. Tissier, note ssCass. req., 23 mars 1903 : S. 1904, I, p. 225.

- M. villey, Critique de la pensée juridique moderne, Dalloz, 1976. 
- F. de Visscher, Du « jus abutendi » : RTD civ. 1913,337.

- H. Ph, Visser't Hooft, Les actes de disposition concernant le corp humain. Quelques remarques philosophiques: APD. t. 24, 1979.

- A. Wager, La clause d'inaliénabilité dans les donations et les legs, RTD civ, 1907.

- F. Zénati, Pour une rénovation de la théorie de la propriété, RTD civ. 1993. 